\title{
La Alianza Bolivariana para las Américas-Tratado de Comercio de los Pueblos (ALBA-TCP): análisis de un proyecto de integración regional latinoamericana con una fuerte dimensión altermundialista*
}

Francisco Javier Ullán de la Rosa ${ }^{1}$

\section{Resumen}

El ALBA-TCP es una de las organizaciones internacionales de más reciente creación. Es, sin duda, un proyecto original, diferente a las fórmulas de integración regional conocidas y preexistentes: fuertemente dirigido desde lo político, se propone como un mecanismo para planificar desde lo público las relaciones económicas y comerciales entre países, evitando o reduciendo en lo posible la competencia de mercado y fomentando la cooperación y las sinergias desde valores socialistas y de solidaridad. Y todo esto como expresión de una encrucijada ideológica donde crecen y se mezclan, con la lógica del collage posmoderno, casi todas las corrientes del pensamiento social de izquierda. El ALBA y los gobiernos que lo integran se encuentran en medio de una confrontación geopolítica e ideológica de escala continental que sesga enormemente la objetividad de los análisis. Este artículo pretende superar dichos sesgos presentando un análisis académico riguroso y sin toma de partido alguno. En él se analizan las circunstancias históricas que envuelven el nacimiento y evolución del ALBA y se incursiona en el análisis de su programa ideológico y sus proyectos concretos, señalando su convergencia con los del movimiento altermundialista latinoamericano y mundial. Por último, se apuntan algunas estadísticas de desarrollo concretas a fin de valorar los resultados en la práctica de las políticas económicas de este bloque regional.

\footnotetext{
* Recebido em 09/06/2011. Aprovado em 23/06/2011.

1 Professor of Sociology,University of Alicante (Spain). E-mail: javier.ullan@ua.es
} 
Palavras-chave: ALBA-TCP. Altermundialismo. Acuerds Comerciales, Integración Regional, Socialismo del Siglo XXI.

\section{El nacimiento del ALBA-TCP en el crisol contemporáneo de las izquierdas latinoamericanas.}

El proceso de construcción del bloque regional latinoamericano que responde al prolijo nombre de Alianza Bolivariana para las Américas-Tratado de Comercio de los Pueblos, popularmente más conocido por sus siglas ALBA, tiene sus orígenes en el proyecto político del Socialismo del Siglo XXI de Hugo Chávez, presidente de Venezuela desde febrero de 1999. Fue ese mismo año cuando Chávez presentó por primera vez el embrión de lo que más tarde sería el ALBA bajo el nombre de Confederación de Estados de América Latina. Nombre que pone de manifiesto la voluntad de su promotor inicial de someter desde el principio la dimensión económica a lo político (MANSUR; MORALES, 2007; FERMÍN; EUDIS, 2009). La propuesta, sin embargo, no recogió el eco internacional esperado. Habría que dejar pasar otros dos años para que, en el seno de la Tercera Cumbre de Jefes de Estado de la Asociación de Estados del Caribe en 2001 (ALBA, 2010) las propuestas de Chávez comenzaran a ser escuchadas con seriedad. En este foro Chávez propuso de nuevo impulsar una integración regional en América Latina como alternativa a la propugnada por aquellos mismos años por Estados Unidos bajo la figura de la Asociación de Libre Comercio para las Américas (ALCA). Su propuesta, que ya bautizó como ALBA (por entonces acrónimo de Alternativa, y no Alianza, Bolivariana para las Américas), era la de una integración no reducida a la dimensión económico-comercial, como propugnaba el ALCA, sino articulada desde un proyecto más amplio de naturaleza político-cultural y desde principios de solidaridad y complementariedad comercial planificada, más que de competencia y libre mercado. El primer país en recoger la invitación fue la Cuba castrista. Juntos, Venezuela y Cuba pondrían la primera piedra de este nuevo edificio regional el 14 de diciembre de 2004 (ALBA, 2010).

El bloque comenzó a aumentar y alcanzar masa crítica en 2006 con la adhesión de una Bolivia apenas conquistada democráticamente por el M.A.S. (Movi- 
miento al Socialismo) de Evo Morales y García Linera, con similitudes ideológicas con el Socialismo del Siglo XXI de Chávez pero también con sus características idiosincráticas, las que emanan de su ideología indianista y que se incorporarían al edificio en construcción del ALBA, imprimiéndole un ligero cambio de diseño. Así, por ejemplo, el ALBA añadió al proyecto inicial de Chávez la propuesta del M.A.S. de establecer un Tratado de Comercio de los Pueblos. El ALBA se convierte de esa manera en el ALBA-TCP (ALBA, 2010). Otras adhesiones llegarían en los años sucesivos conforme toda una serie de gobiernos de izquierda, de corte ideológico semejante, van accediendo al poder en la región: la Nicaragua que vive el regreso de los sandinistas (enero 2007), la pequeña Dominica(enero 2008), la Honduras de un convertido Zelaya (agosto de 2008), San Vicente y las Granadinas, Antigua y Barbuda en 2009 y, finalmente, en junio de ese mismo año, Ecuador, tras la victoria de la Alianza País encabezada por Rafael Correa, cuya composición político-ideológica es muy semejante a la boliviana (alianza de mestizos y criollos de izquierdas y organizaciones y partidos indígenas). La adhesión de Ecuador se produjo en una cumbre, la séptima, en la que el ALBA, sin cambiar de siglas, muda su primer apellido de nacimiento, Alternativa, por el de Alianza. En octubre de 2009, el nuevo presidente de Paraguay, el ex obispo y teólogo de la liberación Fernando Lugo, también expresó su voluntad de incorporar su país al ALBA-TCP pero a fecha de hoy esa decisión parece haber quedado aparcada por la oposición de un parlamento paraguayo dominado por el Partido Colorado, de corte derechista. Los últimos países en coquetear con el grupo del ALBA han sido Guyana y Surinam, sin que tampoco se hayan unido todavía a la alianza como miembros de pleno derecho (GOBIERNO BOLIVARIANO DE VENEZUELA, 2010).

El ALBA-TCP es apenas un recién nacido en la arena de las organizaciones internacionales. Más allá de todos los juicios de valor que se han hecho y puedan hacerse al respecto, puede decirse de él que es, sin duda, un proyecto original, diferente a las fórmulas de integración regional conocidas y preexistentes. Y esta originalidad justifica por sí misma plenamente un análisis del fenómeno desde las ciencias sociales. Se define a sí mismo como fuertemente dirigido desde lo político (no podía ser de otra manera, pues está impulsado por gobiernos que abogan por la masiva intervención del Estado en la organización y regulación de la economía), que no descuida los factores económicos como el crecimiento, la industrialización y 
la productividad pero que quiere ponerse al servicio del desarrollo social mediante la promoción de la cooperación, la solidaridad y la complementariedad. Se propone como un mecanismo para planificar desde lo público las relaciones económicas y comerciales entre países, evitando o reduciendo en lo posible la competencia destructiva y fomentando la cooperación y las sinergias. Y todo esto como expresión de una encrucijada ideológica donde crecen y se mezclan, con la lógica del collage posmoderno, casi todas las corrientes del pensamiento social de izquierda, las más antiguas y las más recientes- a veces fuertemente entretejidas- que han florecido en América Latina en los últimos dos siglos: el panamericanismo de los criollos liberales (NAIM, 2004), el anarquismo y el agrarismo; el indigenismo (a la vez pan-americanista y particularista); el populismo (LACLAU, 1977); el desarrollismo de la CEPAL y sus teorías geopolíticas de la dependencia (PREBISCH, 1963; TUSSIE, 2009); el anti-colonialismo y el imperialismo del Movimiento de los No Alineados (AZZI; HARRIS, 2006); el marxismo-leninismo (en particular en su versión tercermundista y latinoamericana representada por Guevara y Castro); la Teología de la Liberación; el federalismo - por qué no- de inspiración europea (AZZI; HARRIS, 2006; CABRERA, 2010) y, finalmente, toda la gama de corrientes que se pretenden hijas legítimas de la posmodernidad: desde el ecologismo al feminismo pasando por el neo-marxismo humanista, el neo-anarquismo, el pacifismo, la transmutación del indigenismo en indianismo y, por último, con un gran peso e influencia, el movimiento altermundialista de contestación al proceso de globalización neoliberal. El ALBA-TCP se puede considerar así como un retoño de los desarrollos ideológicos de la posmodernidad, uno y múltiple a la vez, construido sobre la base de la heterogeneidad y la difuminación de los límites categóricos. Por eso el ALBA-TCP es un proyecto que se reclama a la vez total (proyecto político, económico, social, identitario, cultural, filosófico y moral) y heteróclito, que trata de recopilar toda esta diversidad de voces y articularlas en sólo un discurso polifónico. Y, a pesar de las dificultades y de ciertas contradicciones ideológicas imposibles de ocultar este discurso resulta razonablemente coherente. Al menos como discurso.

Tres ingredientes principales predominan en este potaje abigarrado de ideologías que es el ALBA-TCP: 1) Un proyecto pan-nacionalista de confederación política (NAIM, 2004; MANSUR; MORALES, 2007 ) que incluirá, en la visión de Chávez, incluso la dimensión militar (MANSUR; MORALES, 2007; ALTTMAN, 2008) 2) un 
proyecto estatista de desarrollo bajo el ya clásico modelo de sustitución de importaciones (desarrollo endógeno por un Estado "productor" y fuertemente regulador) (ALTTMAN, 2008 ) y 3) un internacionalismo altermundialista lanzado desde América Latina para sí misma pero también para todo el planeta, con el objetivo de construir un mundo multipolar, sostenible, y más igualitario. Esos son los cotiledones de la semilla del ALBA, que acaba de plantarse. Una naturaleza polimórfica que ha querido expresarse plásticamente en su mismo nombre, edulcorado por los tonos literarios que forman parte de propia esencia humanista y utópica de la tradición filosófica, preñada de estética barroca, de la izquierda latinoamericana. Si la palabra "Bolivariana" deja traslucir la doctrina pan-americanista que tiene en Simón Bolívar su referente icónico -aunque él no haya sido ni el primero ni el único en predicarla ${ }^{2}$ (FERMÍN; EUDIS, 2007)-, las palabras "Alternativa" y "ALBA" introducen la idea de un proyecto de alteridad, de visión política y económica "alternativa"- también se podría llamar "heterodoxa"- que nació al mismo tiempo que el movimiento antiglobalización, como una rama de su mismo tronco (SAGUIER, 2007). La sigla ALBA en sí misma pretende ser un juego de palabras, un acrónimo alternativo al "otro" de su némesis, el ALCA, cuya existencia o su potencialidad de existencia le dio su primera razón de ser. Una sigla que altera sin destruir por completo la estructura del acrónimo al que se opone, que sigue siendo reconocible: una metáfora muy elaborada para transmitir la idea de que el ALBA, como el altermundialismo en sí, no niega la globalización o el sistema-mundo, y mucho menos las relaciones comerciales internacionales, pero quiere deconstruirlas y volverlas a construir con otra molde, cambiando algunas letras, algunos de los pilares de su estructura. "Otro mundo es posible", dice el lema altermundialista con el que quiere animar a las masas a luchar cada día para contribuir a su despegue. En su discurso, el ALBA también se afirma partera de esta alter-visión de la historia y se inviste del papel de portador de un nuevo amanecer, aurora, "alba" de la civilización, que vendría a iluminar el mundo con la luz de un nuevo humanismo.

2 Los documentos oficiales del ALBA mencionan una larga lista de "precursores" históricos de su programa pan-latinoamericanista y antiimperialista: Pueyrredón, O'Higgins, San Martín, Monteagudo, Sandino, y, naturalmente, el “Apóstol” José Martí, el héroe nacional cubano, sometido por la historia al mismo proceso de santificación que Bolívar en Venezuela (ALBA, 2010; FERMíN ET EUDIS, 2007). 


\section{2 ¿El ALBA como “Eje del Mal” Latinoamericano? El bloque regional bolivariano en el ojo de un huracán geopolítico}

Sin embargo, esa imagen rósea con que los muñidores del ALBA publicitan su propuesta contrasta con la Leyenda Negra que sus detractores han ido tejiendo en torno a ella. El ALBA no es el único proyecto que propone una reforma de la división internacional de la economía y del comercio. En las últimas décadas los intentos de reestructuración de las lógicas y los desequilibrios de la economía global se han, de hecho, multiplicado por todo el mundo, siendo los más significativos los defendidos por unos pocos grandes bloques regionales (como el Mercosur) y las potencias emergentes (como Brasil, India, China). Estas resistencias han, de hecho, cosechado algunos resultados significativos: a las potencias emergentes se debe, por ejemplo, el fracaso de la Ronda de Doha (BALDWIN, 2006) y en el aborto del ALCA tuvieron tanto protagonismo los esfuerzos de Chávez y Morales por combatirlo con su alternativa como los grandes países del Mercosur celantes de su propio bloque (FRITZ, 2007; TUSSIE, 2009). La arena de las negociaciones comerciales internacionales ha estado siempre trufada de retóricas bélicas (y de alianzas, contra-alianzas y maniobras hostiles virtuales) pero contra el ALBA se ha abatido una ola de hostilidad política y mediática absolutamente desproporcionada en relación con el modesto peso que tiene su bloque de naciones, sea en el terreno geopolítico (carece apenas de capacidad de acción o presión en sus foros más importantes, como la ONU, la OMC o el G- 20 (AZZI; HARRIS, 2006) ) o en el terreno estrictamente económico (el PIB conjunto actual de su 8 miembros es ligeramente inferior al de Argentina en solitario (CIA 2010). Un fenómeno cuya explicación debe buscarse en el peso que la dimensión geopolítica tiene en este asunto (NAIM, 2004).

Desde su nacimiento el ALBA-TCP ha quedado atrapado en una lógica de confrontación geopolítica que es descrita por la propaganda más radical de ambos lados en términos que recuerdan a épocas pasadas, como si se tratara de una repetición de escenarios políticos de la Guerra Fría: en términos de lucha entre el marxismo y la democracia liberal (entre los críticos del ALBA), entre imperialismo y anti-imperialismo (entre sus sostenedores). América Latina está reviviendo, en paralelo y como consecuencia del proceso de construcción del ALBA, una nueva edición de la sempiterna confrontación entre las fuerzas nacionalistas de izquierda 
y el gobierno de EE.UU., el centro del sistema-mundo capitalista en general y sus aliados nativos en Latinoamérica. Y, como en el pasado, las fuerzas que se oponen al proyecto heterodoxo han desplegado toda la panoplia de estrategias a su alcance, desde la injerencia directa a la diplomacia, pasando por la guerra mediática y académica. Y todo ello en el contexto de una era que se anuncia a bombo y platillo como post-bipolar. Valgan como muestra los siguientes botones. El primer ataque directo contra las ideas que hay detrás del ALBA ocurrió antes de nacer esta y fue dirigido contra el cuartel general del que después sería su primer valedor: en 2002 las fuerzas de oposición de la derecha venezolana orquestaron un confuso golpe de Estado contra el presidente Chávez proclamando durante algunas horas al presidente de las Cámaras de Comercio (precisamente de comercio) como jefe de gobierno. Algunos autores han aportado indicios que apuntan a la complicidad de la administración norteamericana en la preparación del golpe (VULLIAMY, 2002, FORERO, 2004). Pero, en cualquier caso, si no directamente apoyada por las potencias occidentales, la jugada recibió al menos señales positivas de aprobación desde los EEUU y la Unión Europea, ya fuera por parte de ciertos gobiernos - entre ellos el de España (VULLIAMY, 2002; CLARK, 2003)- o de los medios de comunicación (BARTLEY; O’BRIAIN, 2003). Después de dos días de enfrentamientos en las calles el golpe fracasó, dejando como triste saldo un puñado de muertos cuya autoría aún se imputan mutuamente chavistas y antichavistas (PALACIOS, 2004). Pero la oposición no se dio por vencida: se transmutó en feroz campaña de petición de un referéndum revocatorio del mandato presidencial. Para obligar a Chávez a convocarlo recurrió a una huelga salvaje que paralizó durante varios meses la empresa petrolera estatal, PDVSA, el motor y corazón del sistema productivo venezolano, poniendo la economía del país de rodillas. El régimen chavista superó la huelga y ganó el referéndum democráticamente, como ha sido reconocido por la comunidad de observadores internacionales (CARTER, 2004).

La virulenta hostilidad de esta estrategia de oposición obtuvo una reacción contraria a la deseada, el mismo tipo de deriva que había causado el embargo y el golpe/invasión de Bahía Cochinos en Cuba 43 años antes: la posición de Chávez y sus aliados se radicalizó, redobló su retórica anti-imperialista y anti-neoliberal, y convirtió su política internacional en prisionera de una manía persecutoria que explicaría en buena medida la deriva autoritaria que el régimen experimenta a partir 
de este momento (tampoco exenta, por cierto, de cierto grado de magnificación e intencionada manipulación demagógica). El fracaso de esta concatenación de maniobras hostiles habría tenido otro efecto secundario inesperado: la materialización del ALBA, en parte como resultado del fortalecimiento del chavismo posterior al golpe, en parte como una estrategia destinada a proteger al régimen bolivariano con un paraguas de legitimidad y apoyo internacional (EL TROUDI, 2005; FERMÍN; EUDIS, 2009).

Venezuela contraatacó, pues, con la creación del ALBA en 2004 pero también con otros actos de fuerte calado internacional como su campaña durante todo ese año en contra de la firma del ALCA (en alianza con Cuba, los movimientos sociales y las organizaciones indígenas de todo el continente entre las que destacaba la figura de un Evo Morales que aún no se había aupado a la presidencia de Bolivia). La puesta en marcha del ALCA, un proyecto que había nacido en 1991 de manos de George H. Bush, estaba ya anunciada para enero de 2006 pero los estados latinoamericanos, dominados por gobiernos de signo izquierdista, decidieron en la IV Cumbre de las Américas en Mar del Plata, en noviembre de 2005, rechazar su firma. La movilización de Chávez y sus aliados fue importante aunque no la única causa en el fracaso final de las negociaciones del ALCA. El siguiente hito sería la salida de Venezuela de la Comunidad Andina de Naciones (CAN) en abril de 2006 (ALTTMAN, 2008), justificada por la decisión de dos de sus miembros, Colombia y Perú, de firmar un acuerdo bilateral de libre comercio con EE.UU. Venezuela adujo que la firma de dichos tratados por parte de estados pertenecientes a un bloque regional que había eliminado muchas barreras comerciales internas equivalían en la práctica a un ingreso indirecto de Venezuela en una zona de libre intercambio comercial con los EEUU que el país no deseaba ni había decidido (FRITZ, 2007). Dichas firmas se inscribían en la estrategia de EEUU tras la derrota de Mar del Plata: impulsar Tratados de Libre Comercio (TLCs) bilaterales con estados aliados de centro-derecha, estrategia que Katz (2006) denomina, muy gráficamente, de "balcanización comercial". La estrategia consiguió, de hecho, provocar la implosión "balcánica" del bloque de integración regional más antiguo de Sudamérica. Pero si la presentación de los TLCs bilaterales como actos agresivos puede tener mucho de elaboración propagandística por parte de los estados del ALBA, no es menos cierto que el proyecto heterodoxo del ALBA se ha enfrentado con actos 
reales de fuerza y presión. Por ejemplo: al día siguiente de la adhesión de Bolivia al ALBA, EEUU derogó el Acuerdo Preferencial de Comercio que tenía con ese país, con claras intenciones punitivas (CABRERA, 2010) y mostró una clara simpatía por el violento alzamiento regional de Santa Cruz contra el gobierno de Morales (GARCÍA MÉRIDA, 2008). El acto más grave de todos lo constituyó, sin embargo, el golpe de Estado del 28 de junio de 2009 perpetrado por el ejército y la derecha de Honduras contra el presidente Zelaya. A pesar de haber sido condenado por todos los organismos y gobiernos internacionales (ONU, OEA, Mercosur, Unión Europea, por supuesto el ALBA, la debutante administración Obama (BBC, 2009) o gobiernos latinoamericanos de tendencia conservadora como el colombiano), el nuevo gobierno nunca fue ni ha sido sometido a ningún tipo de sanción continuada o presión internacional efectiva. EEUU y el Banco Mundial retiraron su ayuda económica en los primeros meses y algunos países europeos llamaron a consulta a sus embajadores. Pero todo ello por un periodo muy breve de tiempo. El golpe de Estado triunfó y el nuevo gobierno de Porfirio Lobo, salido de las urnas en noviembre de ese año, fue reconocido por EEUU y la UE (Los Angeles Times 2009). El golpe pronto logró también uno de los objetivos clave por los que había sido orquestado: el 13 de enero de 2010 Honduras abandonó oficialmente el ALBA-TCP cuya firma en 2008 había hecho saltar todas las alarmas en la derecha de ese país (EL UNIVERSAL, 2010).

El conflicto se ha combatido también en otro frente decisivo cuyo teatro de operaciones son las salas de conferencias de las universidades, las oficinas de los think tanks, la prensa, el mundo virtual de internet y las ondas de los medios de comunicación. Una guerra ideológica combatida con ardor por ambas partes. Sobre los países del ALBA y sobre el ALBA en sí mismo se ha escrito de todo (ALI, 2006): Medios de comunicación tan prestigiosos como Foreign Policy (REICH, 2009), Foreign Affairs (SCHIFTER, 2007), Financial Times (MANDER, 2008), The New York Times (2006), The Washington Post (VARGAS LLOSA, 2009), The Economist (2010), han arremetido de contra el ALBA, haciendo análisis demoledores sobre sus economías presentes y vaticinios apocalípticos sobre sus evoluciones futuras (ELLIOT, 2008; THE ECONOMIST, 2010). Sus políticas de nacionalización han sido acusadas de comunismo y piratería (MORA; LEÓN, 2005); sus dirigentes han sido satanizados como aliados y patrocinadores del fundamentalismo islámico 
(ADL 2006, PEÑA ESCLUSA, 2009); se ha agitado constantemente el espantajo de la dictadura marxista en Venezuela; se ha hablado de la conformación de una "Venecuba" unida (OPPENHEIMER, 2010); se ha rescatado del olvido la vieja teoría del dominó de Foster Dulles (DE BRUIN, 2008), herramienta ideológica de la Guerra Fría que justificó la guerra de Vietnam, o se han querido aportar datos para demostrar la existencia de una guerra subterránea del régimen venezolano contra EEUU (SCHOEN; ROWAN, 2009). Ciertos autores y actores del conflicto, entre ellos prominentes miembros de la administración Bush como Otto J. Reich (2005) han incluso etiquetado el ALBA o sus países integrantes como una rama colateral del famoso "Eje del Mal” bushiano: el "Eje del Mal Latinoamericano" (TEXIER, 2003; FREE REPUBLIC, 2003; CRESPO, 2003; REICH, 2005; EL OJO DIGITAL, 2010). En el otro bando, por su parte, todos los embates se encontraron con las diatribas encendidas, preñadas de histrionismo, clásicas de la teatralidad política de la izquierda latinomericana. $Y$ a veces también con reacciones de inesperada ironía ${ }^{3}$. Pero tampoco han faltado las lluvias de datos que intentan demostrar los efectos positivos de las nuevas políticas tanto a nivel nacional como a nivel del ALBA: los programas de asistencia social, el círculo virtuoso de crecimiento económico en marcha... (ALBA 2010).

¿Cómo explicar toda esta agresividad? Parte de la misma tiene que ver con el hecho de que algunos de los promotores del ALBA son viejos protagonistas de entonces, de la Guerra Fría - como los hermanos Castro en Cuba, Daniel Ortega en la Nicaragua neo-sandinista o los ex-combatientes de las guerrillas de los 70 presentes en el gobierno venezolano (por ejemplo el Ministro de Energía y Economía, Alí Rodríguez Araque (MAXWELL, 2000) y boliviano (el vicepresidente Álvaro García Linera (JOFRE, 2005). Sin embargo, este también sería el caso de otros gobiernos latinoamericanos de izquierdas, como Brasil, Uruguay o el Frente Farabundo Martí de Liberación Nacional (FMLN) en El Salvador, los dos últimos en el poder desde 2009 (DAILY TELEGRAPH, 2009; BREMER, 2009), sin que ello haya despertado reacciones hostiles tan significativas. Sin duda, las reacciones que

\footnotetext{
3 Así saludaba, con fina ironía, Evo Morales, en entrevista concedida a la ONG estadounidense Democracy Now la victoria de Fernando Lugo en Paraguay: "Bienvenido al Eje del Mal” (GÓNZALEZ, 2009)
} 
despiertan el pasado guerrillero de ciertas izquierdas sudamericanas no pueden compararse con la fuerte carga emotiva que tienen en Estados Unidos fenómenos como la dictadura castrista o el sandinismo de Ortega, contra los que se ha combatido directamente, o el nuevo fenómeno del chavismo. También se combatió contra el FMLN, se objetará, pero mientras este, como los gobiernos en Brasil o Uruguay, ha dejado aparcadas definitivamente sus veleidades marxistas y de confrontación con las potencias capitalistas, estos otros siguen estancados en ellas. Paradigmático es el caso de la Venezuela de Chávez, alma mater y sostén principal del ALBA: un régimen que ha vuelto a recurrir (aunque sólo sea parcialmente) a las viejas retóricas y estéticas del marxismo latinoamericano de los años 60 y 70 y que ha experimentado desde su llegada al poder una sustancial deriva autoritaria, reflejada, entre otras muchas cosas en el cierre progresivo de la mayoría de los medios opositores, a las que el régimen denomina el "latifundio radioeléctrico y mediático" (EL PAÍS 2007; EL PAÍS, 2009; VINOGRADOFF, 2009); el acoso (RTVE, 2008) y cierre de comercios pertenecientes a emblemáticas franquicias americanas como Mac Donald's o Wendy (para erigir en su lugar, en un caso concreto, una estatua de Fidel Castro (Libertad Digital Internacional (2010); la infiltración de militares cubanos en el aparato de inteligencia y seguridad del estado (PETIT, 2011) o su apoyo apenas velado a las guerrillas marxistas colombianas (RICO, 2008; EL PAÍS, 2008), todo lo cual condujo al Parlamento Europeo a emitir una dura condena contra Chávez en febrero de 2010 (LA NACIÓN, 2010).

Y, sin embargo, aunque pueda haber, sin duda, una relación muy fuerte entre ciertos países del ALBA y dichas dinámicas herederas de la Guerra Fría, el ALBA como bloque regional y como proyecto en sí mismo es mucho más que una mera excrecencia del chavismo o el castrismo: primero, porque está integrado por otros estados cuyo pedigrí democrático está, al menos de momento, fuera de toda duda, estados que, como el caso de Bolivia, han imprimido también una profunda huella ideológica en la conformación del bloque y sus orientaciones para la acción; y, segundo, porque cuando nos alejamos de las trincheras de la agitprop de ambos bandos y nos trasladamos al terreno de los modelos y políticas económicas que propugna el ALBA las similitudes con el marxismo y el pasado se debilitan sustancialmente. Porque El ALBA no es en absoluto una propuesta basada en un programa marxista ortodoxo, del pasado, sino más bien un proyecto sui generis de 
naturaleza socialdemócrata que se ofrece como una especie de "tercera vía” en Latinoamérica entre el neo-liberalismo y los viejos modelos económicos del estatismo marxista. Una "tercera vía” que Hugo Chávez ha resumido muy sintéticamente con estas propias palabras: "Nuestro proyecto no es ni estatista ni neoliberal; nosotros somos exploradores de la vía media, donde la mano invisible del mercado estrecha la mano visible del Estado: Todo el estado que sea posible, todo el mercado que sea necesario" (CHÁVEZ, EN LINARES, 2007, p. 135).

Muchos indicios demuestran que el ALBA no pretende ser un proyecto anti-sistémico radical o anti-occidental (ELLIOT, 2008) sino un híbrido entre las políticas desarrollistas de ya larga tradición en América Latina y el altermundialismo de raíz humanista. La complejidad de la realidad latinoamericana presente no se reduce de ninguna manera a los patrones bipolares del pasado. ¿Cómo explicar si no que algunos de los países del ALBA estén exportando más a los EE.UU. que otras economías que no pertenecen al bloque? El 15\% del PIB de Venezuela lo constituyen las exportaciones a EEUU, la mayoría en forma de petróleo, y para Nicaragua la cifra es del 26\% contra el 1,6 de Argentina, el 5,5 de Chile y el 5,1 de Colombia (WEISBROT; SCHMITT; SANDOVAL, 2008). ¿Cómo explicar que Honduras y Nicaragua no abandonaran el CAFTA (Tratado de Libre Comercio entre Centroamérica y los Estados Unidos) después de unirse al ALBA, y, por el contrario, que los miembros del Frente Sandinista de Liberación Nacional votaran en bloque su ratificación entusiasta apenas regresaron al poder (ORGAZ, 2008), Presidencia de la República de Nicaragua de 2008? ¿Y cómo explicar entonces la petición de adhesión de Venezuela al Mercosur ${ }^{4}$ - un bloque ideológicamente mucho más “ortodoxo” (FRITZ, 2007)? Para explicar esta decisión venezolana algunos autores han recurrido a expresiones y metáforas tan pintorescas como "esquizofrenia política” (ROMERO, 2006; SANAHUJA, 2009) pero los análisis en ciencias sociales recomiendan siempre huir del sensacionalismo acientífico así como de visiones maniqueas y reduccionistas.

\footnotetext{
4 La adhesión ha sido ratificada por todos los parlamentos del Mercosur excepto el de Paraguay, país que sufre una situación de bicefalia política, con un presidente de izquierdas y un parlamento mayoritariamente derechista.
} 
Varias razones pueden aducirse para explicar la dura oposición que ha enfrentado y sigue enfrentando el ALBA:

1) Su debut en sociedad coincidió con la administración más derechista en EEUU desde la era Reagan.

2) La importancia geoestratégica de Venezuela, quinto productor mundial de crudo y miembro de la OPEP, ha magnificado la preocupación por los discursos antioccidentales y las "amistades peligrosas" de algunos miembros del ALBA, empezando por ella misma: sus posición crítica frente a la política de guerras preventivas norteamericanas (Afganistán, Irak) o los coqueteos diplomáticos y comerciales de algunos de ellos (en especial Chávez) con los regímenes petroleros y anti-norteamericanos de Saddam Hussein (Chávez fue el primer jefe de Estado en visitarlo después de 1991), Gadafi o Irán (con quien Venezuela sella un tratado comercial en 2006 (ELLIOT, 2008). Son probablemente estas jugadas políticas y económicas concretas y no el historial o la imagen marxista lo que haya hecho sonar las alarmas en Estados Unidos: las maniobras de Chávez dentro de la OPEP para mantener alto el precio del petróleo y forzar la sustitución del petrodólar (uno de los pilares de la hegemonía económica norteamericana) por el euro (PAUL 2006; AP 2009); el trueque de petróleo por servicios que opera a través del ALBA y que escapa al mecanismo circular del petrodólar, perjudicando también así los intereses norteamericanos (CLARK, 2003); los planes para crear una gran empresa pública de petróleo en América Latina, "Petroamérica" (MAYOBRE, 2005) que pueda competir con las grandes multinacionales del sector; su agresiva campaña contra el ALCA .... ¿Han provocado el triunfo de la ex guerrilla del FMLN en El Salvador o del "montonero" Múgica en Uruguay reacciones similares? No, porque ellos no se han puesto, como si lo han hecho, en cambio, los líderes del ALBA, en la primera línea de combate para socavar el status quo económico global. El ALBA tuvo su bautismo de fuego en la Cumbre de Mar del Plata, en la que 15 años de estrategia comercial de EE.UU. 
para el continente americano se fueron por la borda en un solo día. El gobierno de EE.UU., poco acostumbrado a perder, digirió mal este fracaso, señalando a Chávez, Morales y al ALBA como los culpables del mismo (SEOANE; TADDEI, 2009). La realidad, como se sabe, es que se trató de una decisión soberana de los gobiernos impulsada por los intereses del bloque del Mercosur, entre los que no estaba, por cierto, Venezuela.

3) Hay también factores que podríamos llamar de psicología social. Por un lado debemos tener en cuenta el papel que juega en todo este drama un conjunto de estados psicológicos que parece ser inevitable: la hybris de los poderosos tolera muy mal el desafío de los pequeños, cuyo antagonista dialéctico no es otro que la rabia de los débiles que se traduce en dogmatismo y victimismo antiimperialista. En cualquier caso cualquiera de los dos estados opuestos provoca visiones distorsionadas de la realidad. Las reacciones que el proyecto del ALBA ha recibido en los países desarrollados han oscilado entre la alarma, la demonización, la ironía o el menosprecio condescendiente. Las reacciones atávicas que despierta en una parte de la sociedad estadounidense la palabra "socialismo" -pensemos que incluso Obama ha sido atacado como "socialista" e incluso "comunista" por los medios conservadores de su país (CBS 2009)- azuzadas por la presencia del histórico archienemigo Castro en el proyecto del ALBA han coadyuvado, sin duda, a forjar entre ciertos sectores norteamericanos (y en menor medida europeos) esa imagen del ALBA como una excrecencia de aquel "Eje del Mal" al que la demagogia política de la administración Bush había dado vida en 2002 (BBC 2002). Venezuela nunca se incluyó oficialmente en la lista de países pertenecientes a dicho "Eje", pero hay que recordar que Cuba era miembro vitalicio de la misma incluso antes de que la misma expresión existiera. En esa línea los detractores euro-norteamericanos del ALBA quisieron leer desde el principio el acercamiento entre Cuba y Venezuela como un deslizamiento del segundo hacia el marxismo ortodoxo sin considerar la posibilidad de que fuera el régimen cubano el que 
estaba, gracias a su asociación con las democracias parlamentarias del ALBA dando los primeros pasos - es cierto que muy tibios todavía y quizá meramente oportunistas- hacia un nuevo modelo de socialismo. La realidad hoy en día, sin embargo, parece inclinarse más por la primera tendencia que por la segunda.

La demonización del proyecto del ALBA refleja una cierta incapacidad para leer el subtexto cultural e instrumental de la comunicación política de los líderes del ALBA. El Occidente no ha sido capaz de hacer otra cosa que tomar en serio, como un acto literal de hostilidad, o tachar de bufonería histriónica el exceso verbal desplegado por líderes como Chávez, Castro, Morales, Ortega o Correa, sin tener en cuenta que todo ese aparato discursivo puede leerse en paralelo como una estrategia calculada de propaganda política destinada a alimentar y conservar unos altos niveles de compromiso por parte de sus bases populares, compromiso que les es absolutamente necesario para mantenerse en el poder frente a la feroz resistencia interna que despierta su proyecto. Para las masas latinoamericanas el discurso anti-imperialista tiene funciones de adrenalina y de cemento político al mismo tiempo. Esa adrenalina se suministra por medio de formas de teatro político exageradamente enfáticas quizá, trufadas de lugares comunes y de tópicos victimistas, fruto de una larga tradición histórica, que ciertamente son diferentes a las empleadas en Norteamérica o en Europa. Esta incomprensión intercultural, aunque puede ser espontánea en algunos sectores de la opinión pública euro-norteamericana, está lejos de ser inocente a nivel de los grupos organizados de interés y de las estructuras de poder. Todo parece apuntar a una estrategia impulsada por campañas de propaganda que son simétricas a las desplegadas por los gobiernos del ALBA, y que se inscriben en una similar tradición histórica: la de la construcción cultural de los enemigos externos como bárbaros peligrosos cuya mera existencia constituiría una potencial amenaza que justifica la política exterior, incluidas las acciones hostiles preventivas. 
4) Por último, el ALBA es un bloque de países pequeños y pobres en comparación con otros países de América Latina, lo que reduce sustancialmente los costes de una política de confrontación con el mismo, ya sea en términos económicos ( la posible pérdida de sus mercados puede sacrificarse en aras de una estrategia geopolítica más importante) o en términos políticos (su peso en el contexto internacional, a pesar de la hipercinética actividad diplomática de Chávez, es pequeño más allá de la esfera simbólica). Es evidente que las reacciones de Estados Unidos y Europa a políticas muy similares (oposición al ALCA o a la Ronda de Doha, relaciones comerciales y políticas con países proscritos como Cuba o Irán) no han sido las mismas cuando los protagonistas fueron, por ejemplo, Brasil o el Mercosur. El Mercosur, por, ejemplo, firmó un acuerdo económico bilateral con Cuba en 2008 (SELA, 2009) sin que la prensa internacional haya hecho sonar las alarmas.

Atrapada en las turbulencias de una atmósfera geopolítica tan polarizada, es muy difícil llevar a cabo una reflexión serena de los aciertos o fracasos del ALBA-TCP. Consciente de la batalla en la que está inmerso el ALBA este trabajo intenta construirse desde el más neutral de los rigores académicos posibles, tratando de tomar distancia de las partes implicadas en el conflicto. El trabajo no pretende, en absoluto, ser una vindicación del ALBA y de sus prácticas pero tampoco una crítica demoledora y apriorística del mismo. Espero sinceramente que esta voluntad de rigor haya sido ya percibida en las páginas precedentes. En ellas se han intentado mostrar brevemente las distorsiones de la realidad urdidas por ambos bandos y se ha dejado claro que no se defiende, como hacen ciertos sectores intelectuales comprometidos ideológicamente con la izquierda, a ningún régimen sólo por el hecho de enarbolar discursivamente las banderas de la solidaridad y la justicia social. Quiero por ello subrayar con firmeza la naturaleza dictatorial del régimen castrista y recordar que existen indicios de una deriva autoritaria de la República Bolivariana de Venezuela. Pero también quiero apuntar la prepotencia y la agresividad de gobiernos como el norteamericano y la demonización exagerada a que han sometido a algunos de los gobiernos del ALBA. 
El ALBA no puede ni debe identificarse exclusivamente con el Socialismo del Siglo XXI de Chávez, aunque eso sea lo que se ha hecho en ciertos círculos. El ALBA no puede ni debe identificarse tampoco en exclusiva con las políticas de Cuba o Venezuela, aunque eso sea lo que se ha dicho en ciertos círculos. El ALBA es otra cosa, es un proyecto y una organización multinacional, multilateral, en la que se agrupan países a los que separan tantas diferencias como similitudes tienen en el proceso que los ha unido: una economía estatalizada y 7 economías de mercado, con pesos diferentes de sus sectores públicos; una dictadura militar, un régimen personalista con tendencias autoritarias crecientes y 6 democracias parlamentarias. No reconocer esto y meter a todos los países del ALBA en el mismo saco de la demonización marxista sería equivalente, de alguna manera, como haber dicho lo mismo de lo mismo de la ONU solo porque en su asamblea se sentaba la Unión Soviética, la misma Cuba o China.

El ALBA es, ante todo y sobre todo, un programa, pues su plasmación en la práctica es aún un embrión que apenas ha empezado a dar frutos. Un embrión que podría incluso ser abortado antes de implantarse definitivamente, pues la carencia de un consenso nacional interno en sus países miembros liga su continuidad a la de los gobiernos concretos que lo promueven. Gobiernos que más tarde o más temprano tendrán que abandonar el poder (y este razonamiento es aplicable a todos, incluida la dictadura castrista). El caso de la salida de Honduras tras la deposición de Zelaya es una prueba fehaciente de la extrema fragilidad del proyecto. Una volatilidad que sitúa al ALBA en una posición muy diferente a la del resto de procesos de construcción regional actualmente en marcha en el planeta. Nos será necesaria una perspectiva histórica, probablemente al menos una década de distancia, antes de que puedan extraerse las primeras conclusiones significativas y empíricamente válidas sobre los resultados -políticos y/o económicos- de este proyecto. Por el momento los datos empíricos sobre los logros concretos del ALBA son muy escasos (HARRIS; AZZI 2006), la mayor parte de la información, como ya hemos visto, es sospechosa de estar contaminada por graves sesgos ideológicos (ELLIOT, 2008) y la mayoría de sus ambiciosos proyectos (ALBA, 2010) están aún en el punto de partida. El ALBA se encuentra en status nascendi, sus estructuras organizativas en 
construcción: el ALBA carece de un tratado constitutivo como el de la Unión Europea, se sustenta sólo sobre declaraciones, y apenas hace un año empezó a dotarse de una estructura institucional permanente (FERMÍN; EUDIS 2009, ALBA, 2010).

Es por ello que un trabajo de investigación honesto, que no pretenda añadir más confusión sobre este fenómeno debe, en nuestra opinión, centrarse por el momento fundamentalmente en el estudio del programa del ALBA, limitando el análisis de la praxis tan sólo a pequeñas y cautelosas incursiones muy bien documentadas. En este sentido los campos posibles de investigación que se ofrecen al académico son por el momento muy limitados. Nosotros, como reto metodológico al que invitamos a participar a todo aquel estudioso que desee acercarse al análisis del ALBA, proponemos los siguientes: a) Análisis de las corrientes de pensamiento que han contribuido a construir el edificio del ALBA, identificando todos los componentes de su ideología, sus orígenes históricos y las relaciones dialécticas o simbólicas entre ellos; b) La identificación y análisis de las relaciones entre los actores sociales (Estados, partidos políticos, movimientos sociales, medios de comunicación y las organizaciones supranacionales) que comparten escenario con el ALBA.

\section{El ALBA y su relación con los Nuevos Movimientos Sociales altermundialistas.}

Fiel a estas recomendaciones, este ensayo propone rastrear y analizar una de las dos grandes ramas del árbol genealógico del discurso ideológico del ALBA-TCP: el alter-mundialismo. Hemos decidido empezar por aquí porque creemos que es la línea más original del fenómeno, la que le da su sello de identidad histórica más genuino. La que nos permite, además, demostrar la relativa novedad y autonomía ideológica del proyecto del ALBA -al menos sobre el papel- con respecto al marxismo castrista y al autoritarismo chavista. Dejamos para otro trabajo el análisis de la otra rama, la del proyecto nacionalista-desarrollista: un fenómeno interesante, pero decididamente menos original.

Lo que distingue a este proyecto de otras “terceras vías" en la historia reciente de América Latina, propuestas y encabezadas por hombres fuertes de izquierda 
hasta cierto punto similares a Chávez, como Torrijos en Panamá (1968-1981), Velasco Alvarado en el Perú (1968-1975), Juan José Torres en Bolivia (1970-1971) o Guillermo Rodríguez Lara en Ecuador (1972-1976) es, precisamente, su alianza con los Nuevos Movimientos sociales (NMS) altermundialistas y su extensión más allá de las fronteras en un red de relaciones supranacionales de la que el ALBA es quizá el nodo más importante pero no el único.

La primera literatura sobre los NMS, desde su nacimiento en las "revoluciones" de Mayo del 68, los definía a partir de sus objetivos, más culturales y sociales que económicos y políticos, y hacía hincapié en su independencia de los mecanismos políticos institucionales. Signos de identidad que les conferían su derecho a ser etiquetados como posmodernos (TOURAINE, 1978; CASTELLS, 1997). Los NMS parecían haber encontrado su razón de ser en el ámbito de la para-política: en las ONGs, los medios de comunicación, las manifestaciones y sit-in, los happenings culturales, los movimientos autogestionarios de barrios y comunidades rurales. Un evento que marcó, desde el contexto latinoamericano, un antes y un después para todos los NMS del planeta fue el Foro Social de Porto Alegre, porque allí convirtieron sus objetivos en globales y se entretejieron todos en una red de alianzas global, transformándose en lo que denominamos alter-mundialismo (POLET, 2008). La siguiente evolución del fenómeno vendría protagonizada por la convergencia de los NMS con la política "formal", una alianza con los gobiernos y partidos de izquierda que decidieron utilizar el nuevo potencial de movilización de estos movimientos para alcanzar o conservar el poder. Ello requirió una adaptación de los rígidos marcos ideológicos de los partidos políticos (marxistas o socialdemócratas) para incorporar el coro polifónico, multívoco y lábil, de ideologías nacidas de los tiempos postmodernos. Dicha convergencia es perfectamente detectable en todos los países que ahora forman parte del ALBA, excepto, quizás, en Cuba. Por citar solo algunos ejemplos: Venezuela, con su Movimiento V República, sostenido por los así llamados Círculos Bolivarianos, asociaciones de la sociedad civil (HAWKINS; HANSEN, 2006; RAMÍREZ, 2006); el MAS en Bolivia, surgido del movimiento indianista-sindicalista de cultivadores de coca (STEFANONI Y DO ALTO, 2007); y la Alianza País de Correa en Ecuador (LUCAS, 2007), de la cual fue un pilar fundamental el partido Pachakutik, brazo político de la Confederación Nacional de Indígenas de Ecuador (CONAIE). Esta articulación entre política 
formal y NMS caracteriza la segunda etapa del movimiento altermundialista, esa que Cassen y Ventura (2010) han denominado "post-altermundialismo". El ALBA puede entenderse en este sentido como la extensión de esta alianza en una red internacional, proceso que habría dado como resultado un "regionalismo post-liberal” (SANAHUJA, 2009) o "neo-internacionalismo" (SEOANE; TADDEI 2009).

¿De qué maneras se habría expresado esta particular articulación postmoderna entre política y NMS en el caso concreto del ALBA? Un análisis detallado del fenómeno nos ha llevado a sintetizarlas en los siguientes puntos.

1) Su pedigrí de nacimiento: el altermundialismo se ha presentado siempre como un antagonista directo de los proyectos de regionalismo neoliberal, ya desde su fase pionera (los neozapatistas levantándose simbólicamente en armas el día de la entrada en vigor del TLCAN, 1 de enero de 1994) y más tarde en su fase de consolidación (la lucha contra la OMC y el proyecto del ALCA fue el catalizador que provocó la fusión de los NMS de cada país en la Alianza Social Continental (ASC) y en el Foro Social Mundial (DEMIRDJAN, 2006; FRITZ, 2007). El ALBA también nació en este contexto. Durante la IV Cumbre de las Américas en Mar del Plata en noviembre de 2005, Morales y Chávez organizaron una puesta en escena muy efectiva junto con la ASC para movilizar a la opinión pública continental en contra del ALCA: se organizó la III Cumbre de los Pueblos, también conocida como la "anticumbre", la caravana del ALBA (ALBA Express) y ambos líderes se dieron un baño de multitudes acompañados por una pléyade de personalidades de las artes y el deporte (SERRANO, 2005; HARRIS; AZZI, 2006). El rechazo al ALCA era un clamor popular que los gobiernos no podían ignorar. En Brasil, una consulta popular organizada en 2002 por más de 60 organizaciones de la sociedad civil había arrojado un rechazo del 90\% (TUSSIE, 2009).

2) La incorporación de los NMS altermundialistas a su estructura institucional: en el contexto de una nueva concepción de la 
democracia (de abajo hacia arriba, participativa) las colaboraciones institucionales entre el ALBA y los NMS son recíprocas. Algunos ejemplos de ello:

- 88 organizaciones de campesinos e indígenas reunidos en el Congreso de CLOC/Vía Campesina en octubre de 2005, hicieron pública la siguiente declaración: "Nos unimos al ALBA y nos comprometemos a contribuir a su formulación, desarrollo y aplicación futura" (HARRIS; AZZI, 2006).

- Los líderes del ALBA asisten con frecuencia a los eventos altermundialistas. En el encuentro "Enlazando Alternativas 2" que se celebró en Viena en 2006, Morales y Chávez se comprometieron a dar participación a los NMS y ONGs en el ALBA (AZZI; HARRIS, 2006).

- Esta promesa se ha hecho realidad en la VI Cumbre del ALBA, en 2008, donde se han dado los primeros pasos para la creación de una estructura institucional permanente para la organización basada en el modelo europeo de los Consejos de Ministros de los gobiernos nacionales. Al mismo nivel jerárquico del Consejo Político, el Consejo de Programas Sociales y el Consejo de Complementariedad Económica se creó el Consejo de Movimientos Sociales (ALBA 2010). Ciertas fuentes independientes, sin embargo, manifiestan el escaso poder de decisión que este Consejo tiene en la praxis, lamentando que hasta ahora la construcción de "abajo hacia arriba" se haya quedado solamente en el papel (AZZI; HARRIS, 2006; Alttman 2008). Sin negar la verdad hay en ello, no debemos subestimar el poder de influencia que los movimientos sociales tienen para alterar los planes de los gobiernos. Un ejemplo notable de esto fue el rechazo de los movimientos sociales a la propuesta de Chávez, en la misma VI Cumbre del ALBA, de introducir un organismo militar, el Consejo de Defensa, en la estructura orgánica del bloque (FERMÍN; EUDIS, 2009). La propuesta de Chávez no fue aprobada y en dicha derrota fue fundamental la firme 
postura del movimiento artermundialista, para quien el antimilitarismo es parte de un credo irrenunciable.

3) Su modus operandi en redes flexibles y de geometría variable: $\mathrm{Al}$ igual que las ONGs altermundialistas, el ALBA, incluso ahora que está en proceso de dotarse de un marco institucional estable y definido, no parece funcionar como una organización supranacional tradicional sino por medio de una especie de federalismo flexible, post-westfaliano y post-estatal (Rojo 2000) que trabaja con la lógica de red descrita por Castells (1997). Los países del ALBA son, así, a la vez miembros de una federación supranacional y nodos autónomos con la capacidad para mantener o crear otras redes: Nicaragua y Honduras son (eran en el caso del segundo) miembros del ALBA y del CAFTA contemporáneamente; Venezuela ha pedido el ingreso al Mercosur, y es miembro de la Comunidad Sudamericana de Naciones (CSN/UNASUR); Ecuador de la CAN y la CSN/UNASUR y todos ellos miembros de la ALADI (Asociación Latinoamericana de Integración) (SELA 2009). Esta lógica de red, copiada del movimiento altermundialista, se extiende también más allá de las instituciones formales de integración regional para crear alianzas bilaterales sólo en ciertos sectores. Así, en Petrocaribe, un programa del ALBA que ofrece petróleo venezolano a precios preferenciales, participan países como Haití o Jamaica, que no pertenecen al ALBA ni a ninguno de los otros organismos latinoamericanos. Lo mismo puede decirse de TVSur, una de las voces mediáticas del ALBA, en el que participan, también, Argentina y Uruguay ${ }^{5}$, o el Banco del Sur, constituido en 2007 por Argentina, Bolivia, Brasil, Ecuador, Paraguay y Venezuela como alternativa al Banco Mundial y en el que ahora también está Colombia. Una red que se extiende también fuera de las instituciones creando alianzas de un nuevo tipo (gubernamental/no gubernamental) entre las ONG y el ALBA: es el caso, por ejemplo, de los proyectos que el MST brasileño lleva a cabo en Venezuela (HARRIS; AZZI 2006).

5 La propiedad es compartida entre Venezuela (46\%), Argentina (20\%), Cuba (19\%), Uruguay (10\%) y Bolivia (5\%) (Fritz 2007; Fermin et Eudis 2009) 
Bajo esta lógica de red el ALBA actúa al mismo tiempo en el ámbito de la política y de la para-política, como la organización supranacional de sello posmoderno que es, y en esa lógica sus fronteras se desdibujan, se vuelven imprecisables, ciertamente no reducibles del todo a las de sus siete $\mathrm{u}$ ocho estados. Esta es una las razones que convierten cualquier intento de demonizar al ALBA - o de clasificarlo en rígidos moldes de confrontación ideológica al identificarlo como un producto exclusivo del chavismo- en un temerario ejercicio de ceguera intelectual. Demonizando al ALBA se están demonizando extensas redes de actores sociales que poco tienen que ver con Venezuela y sus derivas autoritarias. Pero esta estrategia de expansión reticular, aunque factible en la mayoría de las esferas parapolíticas no está exenta de dificultades y conflictos de identidad en terrenos más institucionales, especialmente en el ámbito de los proyectos de integración regional formal, donde las contradicciones pueden ser incompatibles con la lógica de la apertura indiscriminada. El caso de los enfrentamientos que dieron lugar a la salida de Venezuela de la CAN o el rechazo que despierta su integración al Mercosur son la prueba más palpable.

4) La coincidencia casi total entre el manifiesto ideológico y programático del ALBA y el del alter-mundialismo: A demostrarlo dedicaremos el siguiente apartado, en el que se realizará un análisis comparativo entre un manifiesto altermundialista y el programa del ALBA.

\section{Lospuntosprogramáticos delALBAyelmanifiestoaltermundialista de ATTAC: una comparación sistemática.}

Hemos elegido para hacer este ejercicio el manifiesto de ATTAC (Asociación por la Tasación de las Transacciones Financieras y la Acción Ciudadana), una ONG fundada en 1998 en Francia y con una red de representación muy densa en España. Ya hemos descrito los lazos profundos que unen al ALBA con el movimiento anti-globalización en América Latina. Es por eso que queremos ahora alejarnos un poco de ese continente con el objetivo de ofrecer un marco de compara- 
ción lo más amplio posible. La comparación con ATTAC nos permitirá colocar el fenómeno del ALBA en un marco verdaderamente mundial. ATTAC es, por otra parte, hasta ahora, la única ONG radicada en países de la OCDE que, como sus hermanas latinoamericanas, ha logrado resultados concretos en el campo político (fue muy influyente en la victoria del no en el referéndum sobre la Constitución Europea en Francia en 2007 y es una de las organizaciones detrás del movimiento de los "indignados" del mes de mayo de 2011 en España). La comparación con un manifiesto equivalente del ALBA no es posible, puesto que este sencillamente no existe. El programa del ALBA no ha sido todavía sistematizado en un único documento sintético por lo que se utilizarán varios, todos ellos obtenidos de la página web de la organización. Para hacer más gráfico el ejercicio de comparación y poner en relieve sus profundas similitudes, se situarán los extractos de los textos en columnas contiguas. Se complementará el análisis, allá donde se pueda, con ejemplos de la aplicación en la práctica de estos principios por parte del ALBA.

\section{1) Reforma del sistema de naciones unidas y de la OMC}

\begin{tabular}{|c|c|}
\hline $\begin{array}{l}\text { Denuncia de los tratados de libre } \\
\text { comercio [...] Reforma profunda, por } \\
\text { medio de la modificación de sus objetivos } \\
\text { y principios de funcionamiento, de la } \\
\text { Organización Mundial del Comercio } \\
\text { (OMC) [...] del FMI y del Banco Mundial } \\
{[\ldots] \text { e incorporación de esta[s] [...] en el }} \\
\text { sistema de las Naciones Unidas, que debe } \\
\text { así mismo reformarse. (ATTAC, 2006). }\end{array}$ & $\begin{array}{l}\text { La verdadera integración } \\
\text { latinoamericana no puede ser una } \\
\text { criatura del mercado ciego [...] Hay } \\
\text { que luchar por la democratización y } \\
\text { la transparencia de los organismos } \\
\text { internacionales, en particular las } \\
\text { Naciones Unidas y sus instituciones } \\
\text { (ALBA, 2004) }\end{array}$ \\
\hline
\end{tabular}

2) Nuevo orden económico mundial basado en la soberanía de los pueblos (fin del condicionamiento a los intereses de los países desarrollados) y en los principios de solidaridad, cooperación y complementariedad económica 
El [...] objetivo es que los pueblos puedan ejercer su soberanía, [...] Este nuevo orden debe basarse en principios de solidaridad y cooperación selectiva, en función de las situaciones y necesidades de cada uno (ATTAC, 2006)
El ALBA apoya los principios de solidaridad, cooperación genuina y complementariedad entre nuestros países [...] una agenda económica definida por los Estados soberanos libres (ALBA, 2010). Estos principios deben basarse en un tratamiento $[. .$.$] que tenga en cuenta$ el nivel de desarrollo de cada país [...] con el fin de promover una especialización productiva eficiente (ALBA, 2004).

Todos los programas diseñados por el ALBA emanan de estos tres pilares (solidaridad, cooperación y complementariedad). Para dar sólo algún ejemplo podríamos citar la propuesta de creación de un "fondo de convergencia estructural" entre los miembros del ALBA. Inspirado en los fondos estructurales de la UE, aún no ha visto la luz de manera formal y ha operado hasta ahora a través de "donaciones" ad hoc de Venezuela a los países más pobres, como la creación de un fondo de 100 millones de dólares para financiar inversiones producticas en Bolivia (FRITZ, 2007).). Otra medida sería el establecimiento, este sí en funcionamiento, de una tasa de interés preferencial en los bonos argentinos y bolivianos cuando quien los compra es un miembro del ALBA, en este caso Venezuela (FRITZ, 2007).

\section{3) Regulación y tasación de las transacciones financieras interna- cionales}

\begin{tabular}{|r|l|}
\hline $\begin{array}{r}\text { Introducción, cada vez que sea } \\
\text { necesario, de controles en los cambios }\end{array}$ & \multicolumn{1}{|c|}{ Definición de una nueva } \\
y circulación de capitales, combinado & arquitectura financiera internacional \\
con la introducción de un impuesto & {$[\ldots]$ Adopción de mecanismos } \\
sobre las transacciones financieras & que conlleven a la independencia \\
internacionales (ATTAC, 2006). & monetaria y financiera (ALBA, 2010) \\
\hline
\end{tabular}

Venezuela ha introducido en 2009 una medida de corrección cambiaria de este tipo, aplicando dos tipos de cambio diferentes a su moneda: uno, a 2,60 bolívares por dólar, se aplica a las importaciones de productos prioritarios como alimen- 
tos, medicinas y bienes de equipo, mientras que el otro, a 4,30 bolívares por dólar, se utiliza para las mercancías no prioritarias (FRITZ, 2007).

\section{4) Articulación de un proteccionismo comercial con un comercio solidario.}

\begin{tabular}{|c|c|}
\hline $\begin{array}{l}\text { Sustitución del principio de la li- } \\
\text { beralización general de los intercambios } \\
\text { exteriores por una apertura selectiva y } \\
\text { negociada, destinada a fomentar la pro- } \\
\text { ducción local y proteger los sectores prio- } \\
\text { ritarios (por ejemplo, la agricultura y los } \\
\text { bienes culturales) [...] [así como] a pro- } \\
\text { mover el comercio justo (ATTAC, 2006). }\end{array}$ & $\begin{array}{l}\text { Tendrán prioridad los intereses es- } \\
\text { pecificos de los Estados miembros deprote- } \\
\text { ger determinados sectores, especialmente, } \\
\text { sus agriculturas campesinas (Fritz 2007) } \\
\text { [...] Los Tratados de Comercio de los Pue- } \\
\text { blos (TCP) son tratados que buscan sa- } \\
\text { tisfacer las necesidades de los pueblos. No } \\
\text { buscan el lucro. Su objetivo es maximizar } \\
\text { los recursos e incluyen acuerdos de crédito } \\
\text { para facilitar los pagos (ALBA, 2010). }\end{array}$ \\
\hline
\end{tabular}

Un acuerdo de este tipo opera a través de Petrocaribe. A través de esta institución Venezuela abastece de petróleo a los países del Caribe, en especial a Cuba, con condiciones financieras muy flexibles. El programa se ha expandido posteriormente a otros países del continente. Para ir aún más lejos PDVSA creó la filial PDV Caribe que se encarga del transporte del crudo sin beneficio alguno. Pero aún más original en este nuevo paradigma de comercio solidario es el hecho de que Venezuela acepta pagos en efectivo en forma de bienes o servicios (FRITZ, 2007; ALTTMAN, 2008) en lo que parece ser una adaptación para el comercio internacional de la experiencia de las Redes de Trueque que nacieron en Argentina durante la crisis del "Corralito (formalizadas con el apoyo explícito del gobierno de Kirchner) y que se extendieron después por toda América Latina (PRIMAVERA, 2002). Este tipo de transacciones compensatorias tienen como objetivo activar el comercio en economías como las del ALBA que no cuentan con grandes reservas de divisas y poseen en cambio activos difícilmente comercializables a través del circuito monetario: servicios educativos y sanitarios en Cuba, soja boliviana (Bolivia perdió el mercado colombiano cuando este abrió sus puertas en 2006 al dumping agrícola de América del Norte (HARRIS; AZZI, 2006) Así, Cuba paga su petróleo con médicos y maestros, que no podría exportar a ningún otro sitio, y Bolivia hace lo mismo 
con su producción agrícola. Venezuela también paga a sus socios en especie: aparte de petróleo, con transferencias de tecnología, por ejemplo (FRITZ, 2007). Además de la dimensión solidaria la estrategia tiene una dimensión claramente geopolítica: debilitar el poder del dólar en la región y hacer frente a las políticas comerciales de los Estados Unidos (embargo a Cuba, tratados bilaterales de libre comercio). El caso boliviano nos proporciona todavía otros ejemplos ilustrativos de esa apertura selectiva y complementaria: las exportaciones bolivianas se benefician de la plena liberalización de aranceles y medidas no arancelarias frente a sus socios cubanos y venezolanos mientras que, en cambio, Bolivia no ha eliminado sus barreras salvo en el caso de las exenciones fiscales a la inversión en su territorio de empresas públicas de los demás miembros del ALBA (FRITZ, 2007).

Pero el gran proyecto que apunta a construir la independencia económica y comercial de América Latina, uno de cuyos mayores obstáculos es la escasez de reservas en divisas, se llama SUCRE (acrónimo de Sistema Único de Compensación Regional), un proyecto de moneda común que vuelve a evocar en sus siglas una polisemia rica de intencionalidades políticas. Sucre fue, como Bolívar, otra de las grandes figuras históricas de la Independencia Latinoamericana, el fundador de Bolivia, pero también el nombre de la antigua moneda ecuatoriana, sustituida por el dólar en 2000). Dice el ALBA al respecto del SUCRE: En su primera fase (iniciada en 2010) el SUCRE [...] se utilizará únicamente como una unidad de cuenta entre los Bancos Centrales de los países miembros, para el pago de transacciones comerciales. En una segunda fase también servirá como unidad de cuenta común entre exportadores e importadores y, finalmente, en su fase de consolidación conducirá a la puesta en circulación de una moneda que tendrá valor como medio de pago y de reserva entre los países miembros y sus respectivos mercados. El sistema de pagos se aplicará en el marco del Tratado de Comercio de los Pueblos en aplicación del principio de solidaridad entre aquellos Estados con superávit y aquellos con déficit crónico (ALBA, 2010).

\section{5) El Desarrollo Humano como objetivo y no el crecimiento económico en sí mismo.}

El Desarrollo Humano es un concepto desarrollado en los años 90 desde el equipo económico de la ONU y del cual se inspira directamente el concepto huma- 
nista de desarrollo propugnado por el ALBA, el que se ha oficializado en el nombre acuñado por la versión indianista del mismo (los movimientos indígenas quieren encontrar sus raíces en la ética social indígena): el "Sumak Kawsay” (en quichua) o Suma Qamaña (en aymara), traducido al castellano como "el Buen Vivir"6.

\begin{tabular}{|l|l|}
\hline $\begin{array}{r}\text { El objetivo del desarrollo debe } \\
\text { ser la satisfacción de las necesidades }\end{array}$ & $\begin{array}{l}\text { El ALBA da prioridad a la justicia } \\
\text { social por encima del mercantilismo. De } \\
\text { sociales (ATTAC, 2006). }\end{array}$ \\
& $\begin{array}{l}\text { educación y salud para todos y todas, el } \\
\text { turismo social, el deporte, la vivienda. } \\
\text { Hacer realidad lo que Simón Bolívar llamó } \\
\text { "la felicidad del pueblo" (ALBA, 2010). }\end{array}$ \\
\hline
\end{tabular}

Esta política humanitaria había comenzado incluso antes de la fundación del ALBA con las Misiones Bolivarianas en Venezuela, en las que participaron miles de profesionales cubanos. Como parte de la Misión Barrio Adentro, 30.000 médicos y enfermeros cubanos prestaron servicios en Venezuela. La otra gran Misión, contra el analfabetismo, se bautizó Robinson. Con la ampliación del ALBA los intercambios de trabajadores humanitarios se han multiplicado (FRITZ, 2007; ELLIOT, 2008) enmarcándose en una estrategia de desarrollo social, más ambiciosa: la de los Proyectos Grannacionales (ALBA, 2010).

\footnotetext{
6 Así define el PNUD el concepto de Desarrollo humano: El proceso de ampliación de las opciones de las personas y mejora de las capacidades humanas (la diversidad de cosas que las personas pueden hacer o ser en la vida) y las libertades, para que las personas puedan vivir una vida larga y saludable, tener acceso a la educación y a un nivel de vida digno, y participar en la vida de su comunidad y en las decisiones que afecten sus vidas. (http://hdr.undp.org/es/desarrollohumano/). Y así lo define uno de sus padres, el economista Amartya Sen, citado en la misma página web del PNUD: "El desarrollo humano, como enfoque, se ocupa de lo que yo considero la idea básica de desarrollo: concretamente, el aumento de la riqueza de la vida humana en lugar de la riqueza de la economía en la que los seres humanos viven, que es sólo una parte de la vida misma”.
} 


\section{6) Desarrollo sustentable y ecologismo.}

\begin{tabular}{|l|l|}
\hline La protección del medio & $\begin{array}{l}\text { Debemos promover el desarrollo } \\
\text { sostenible por medio de normas que } \\
\text { protejan el medio ambiente, fomenten }\end{array}$ \\
ambiente, de los recursos [...] y el & el uso racional de los recursos y eviten \\
desarrollo de las energías renovables & la proliferación de patrones de consumo \\
con los siguientes objetivos: reducir el & basados en el despilfarro (ALBA, 2004). \\
consumo de energía (ATTAC, 2006). & $\begin{array}{l}\text { Sepropone una integración basada en una } \\
\text { relación diferente de la humanidad con la } \\
\text { naturaleza (HARRIS; AZZI, 2006). }\end{array}$ \\
\hline
\end{tabular}

El ecologismo profesado por el discurso del ALBA adquirió, con la adhesión de Bolivia, tonos incluso religiosos que se han incorporado en el texto del ALBA. El MAS hizo suyos los principios de la cosmovisión animista indígena que contempla la naturaleza no sólo como un ser vivo con derechos sino como una manifestación de la sacralidad panteísta andina (la Pacha Mama, la Madre Tierra).

7) Estatalización parcial de la economía. Creación de grandes empresas públicas internacionales.

\begin{tabular}{|l|l|}
\hline Ningún servicio público estará & $\begin{array}{r}\text { El ALBA se opone a las reformas } \\
\text { que tiene por objetivo la desregulación } \\
y \text { la privatización de los servicios } \\
\text { sujeto a las leyes de la competencia. } \\
\text { Apoyamos el fomento de empresas } \\
\text { públicos (Fritz 2007). En este sentido } \\
\text { gestión [...] de los bienes comunes [...]: } \\
\text { el agua, el clima, la energía, los recursos ha creado el concepto de } \\
\text { no renovables, la vida, las semillas, el } \\
\text { conocimiento (ATTAC, 2006). }\end{array}$ \\
$\begin{array}{l}\text { de gestión orientados a privilegiar la } \\
\text { producción de bienes y servicios que } \\
\text { satisfagan las necesidades humanas } \\
\text { (ALBA, 2010). }\end{array}$ \\
\hline
\end{tabular}

El término "Grannacional" es de nuevo una apuesta por la simbología política que se presenta intencionalmente como sustituto y rival del tan demonizado “Transnacional”. Muchas de estas Empresas Grannacionales todavía están en fase 
de proyecto, pero algunas ya han comenzado a operar. Aquí presentamos una lista de todas las propuestas y del estado que se encuentran. Fieles al proyecto humanista, algunas de las empresas más allá de las actividades estrictamente económicas (ALBA, 2010):

\begin{tabular}{|c|c|}
\hline Finanzas & $\begin{array}{l}\text { Banco del ALBA, fundado en } 2008 \text { con un capital inicial de } \\
1000 \text { millones de dólares (Alttman 2008). }\end{array}$ \\
\hline $\begin{array}{l}\text { Ciencia y } \\
\text { tecnología }\end{array}$ & Centro de Ciencia y Tecnología (en proyecto) \\
\hline Alimentación & $\begin{array}{l}\text { Grannacional de producción de alimentos (en proyecto) } \\
\text { Empresa Mixta Socialista de Pesca Industrial del ALBA } \\
\text { (Pescalba) }\end{array}$ \\
\hline Energía & $\begin{array}{l}\text { El proyecto inicial de Petroamérica (MAYOBRE, 2005) } \\
\text { pretende substituirse por el más ambicioso Empresa } \\
\text { Grannacional de Energía Eléctrica, Petróleo y Gas (en } \\
\text { proyecto). Por el momento está en funcionamiento } \\
\text { Petroandina, empresa mixta boliviano-venezolana y varios } \\
\text { partenariados de PDVSA con otras petroleras públicas. }\end{array}$ \\
\hline \multirow[t]{2}{*}{ Medio ambiente } & $\begin{array}{l}\text { Grannacional para la gestión de los bosques y la producción } \\
\text { y comercialización de la madera (en proyecto) }\end{array}$ \\
\hline & Agua y alcantarillado. \\
\hline \multirow{2}{*}{$\begin{array}{l}\text { Salud } \\
\text { (Albamed, en } \\
\text { funcionamiento) }\end{array}$} & $\begin{array}{l}\text { Grannacional de distribución y comercialización de } \\
\text { productos farmacéuticos (ALBAMED, en proyecto) }\end{array}$ \\
\hline & Centro de certificación del registro sanitario (en proyecto). \\
\hline Vivienda & Grannacional de cemento (en proyecto) \\
\hline \multirow[t]{2}{*}{ Comercio justo } & $\begin{array}{l}\text { Grannacional de importación y exportación, ALBAEXIM } \\
\text { (en proyecto) }\end{array}$ \\
\hline & Tiendas del ALBA \\
\hline $\begin{array}{l}\text { Telecomunicacio- } \\
\text { nes }\end{array}$ & Grannacional de Telecomunicaciones (en proyecto) \\
\hline \multirow{4}{*}{$\begin{array}{l}\text { Cultura y } \\
\text { educación }\end{array}$} & Fondo cultural del ALBA \\
\hline & $\begin{array}{l}\text { Proyecto Grannacional de alfabetización, post- } \\
\text { alfabetización y Universidad del ALBA (UNIALBA) (en } \\
\text { proyecto) }\end{array}$ \\
\hline & Juegos deportivos del ALBA \\
\hline & Turismo social \\
\hline
\end{tabular}


8) Fomento del cooperativismo y de fórmulas colectivas de propiedad y gestión empresarial.

Es necesario, en paralelo con el fortalecimiento de las empresas públicas, fomentar el desarrollo de otras formas de propiedad y gestión, en especial las mutuas y cooperativas, fortalecer la representación de los trabajadores en la toma de decisiones de la empresa y la ampliación del papel de las organizaciones de trabajadores y consumidores en la empresa (ATTAC, 2006).
El ALBA-TCP quiere que el comercio sea útil para el fortalecimiento de los pequeños productores, microempresarios, cooperativas y empresas comunitarias $y$ defiende, en consecuencia, la limitación de los derechos de los grandes capitalis$\operatorname{tas}[\ldots]$

Chávez ha propuesto la creación de una red regional de empresas recuperadas [...] empresas que fueron llevadas a la quiebra por sus dirigentes, con el nombre de la Empresas Recuperadas del Sur (EMPRESUR). Además ha anunciado la creación de un fondo de 5 millones de dólares para estas empresas de autogestión (FRITZ, 2007). Chávez espera que EMPRESUR se convierta en el vivero de una nueva generación de empresas multinacionales pero de propiedad de los trabajadores (FRITZ, 2007).

\section{9) Protección de la propiedad intelectual}

\begin{tabular}{|l|l|}
\hline $\begin{array}{l}\text { Protección de la propiedad intelectu- } \\
\text { al, de acuerdo con principios de soli- } \\
\text { daridad con los países menos adelan- } \\
\text { tados (ATTAC, 2006). }\end{array}$ & $\begin{array}{l}\text { Con medidas para garantizar que las } \\
\text { normas de propiedad intelectual prote- } \\
\text { voracidad de las empresas transnacio- } \\
\text { nales y no se conviertan en un obstáculo } \\
\text { para el desarrollo (ALBA, 2004). }\end{array}$ \\
\hline
\end{tabular}

Nos encontramos de nuevo ante una medida de protección selectiva. El ALBA quiere eliminar los obstáculos a la transferencia de tecnología en ciertos sectores pero se opone enérgicamente, como el movimiento altermundialista, en otros como, por ejemplo, en el tema de la importación de semillas y animales transgéni$\cos (\mathrm{OGM})$ (ATTAC, 2006).

10) Defensa y promoción de la diversidad cultural. 
Hay que defender la diversidad cultural para contrarrestar el formateo de las mentes (ATTAC, 2006).
Un sistema de diversidad cultural y no de aplastamiento de culturas e imposición de valores culturales y estilos de vida ajenos a las realidades de nuestros países [...] Defensa de la cultura latinoamericana y caribeña y de la identidad de los pueblos de la región, con particular respeto y fomento de las culturas autóctonas e indígenas. Creación de la Televisora del Sur (TELESUR) como instrumento alternativo al servicio de la difusión de nuestras realidades (ALBA, 2010)

\section{1) Reforma de la democracia parlamentaria}

A través de varios canales:

- Garantizar la plena participación de las mujeres en la vida democrática (ATTAC, 2006). El artículo 88 de la Constitución Bolivariana de 1999 es pionero en el mundo en este sentido, debido a que reconoce el trabajo doméstico como actividad económica que genera valor añadido y por lo tanto la concesión del derecho a la seguridad social para las amas de casa (ELLIOT, 2008). El ALBA-TCP, también ha hecho su contribución mediante la propuesta de inclusión del Consejo de la Mujer en su organización, aunque aún no es una realidad.

- Establecer el derecho de iniciativa legislativa de los ciudadanos $y$ de referéndum por iniciativa popular a todos los niveles. [...] la prohibición de prolongación indefinida de mandatos [...]. Inspirándose en la Constitución de Venezuela, introducir en la Constitución Francesa la posibilidad de referendum revocatorio a mitad de mandato. Generalizar e institucionalizar el rendimiento de cuentas de todos los cargos electos. Implantar la elaboración de presupuestos participativos en todas las instituciones. Dar poder real de intervención y medios para hacerlo a las asociaciones de vecinos (ATTAC, 2006). 
Este último punto es donde, por razones que nos devuelven al terreno de la geopolítica y sus pulsos internacionales, el programa de ATTAC y el del ALBA toman un poco de distancia. ATTAC es un movimiento civil que nunca ha ejercido ni ejercerá el poder. El ALBA está impulsado, en cambio, por un grupo de gobiernos y sus programas en favor de una democracia participativa, de bases, asamblearia y referendaria se ven frenados por los engranajes de la realpolitik y por la necesidad de mantenerse en el poder en un entorno internacional y doméstico plagado de adversarios. Así, es evidente que estas recomendaciones no han llegado todavía a los oídos de los hermanos Castro. En Venezuela, que ATTAC curiosamente toma como ejemplo muchas de estas medidas se han aplicado pero con una notable excepción: la prohibición de la extensión de los mandatos presidenciales. Por el contrario, el presidente izquierdista ha maniobrado constantemente para ampliar su mandato con el argumento de la necesaria consolidación de la revolución. Pero a pesar de ello ATTAC sigue defendiendo a capa y espada al régimen bolivariano, justificando incluso algunas de sus medidas más controvertidas, como el acoso a los medios de comunicación que se niegan a aceptar una ley que les obliga a someter su programación a una regulación de contenidos (ATTAC, 2010).

\section{A modo de conclusiones: la necesaria separación analítica entre programa, políticas y resultados económicos.}

El ALBA-TCP es un proyecto de carácter profundamente político y politizado y por esta misma razón su supervivencia todavía no está asegurada. Esa es la lección que nos enseña el caso de Honduras. A diferencia de otros proyectos de integración más ortodoxos, que tienen un amplio consenso político en el seno de sus naciones, el ALBA es un proyecto muy controvertido que surge de las izquierdas con la oposición radical de las derechas e incluso de corrientes centristas más moderadas y su continuación parece depender por el momento de los equilibrios internos de poder. ¿Qué pasará con el ALBA en una posible Venezuela post-bolivariana? ¿O en Nicaragua cuando salga el gobierno del FSLN? ¿O en la transición cubana, no importa cuándo ocurra esta? El ALBA acaba de despegar si pero ¿se verá obligado a hacer un aterrizaje de emergencia en pleno vuelo? El ALBA es una cristalización en el terreno de las relaciones internacionales de algunos de los pro- 
gramas de los movimientos altermundialistas planetarios de izquierda. El ejercicio comparativo entre los principios del ALBA y el manifiesto de uno de los representantes más significativos de dicha corriente en Europa, ATTAC, nos ha servido para demostrarlo.

Un análisis racional y científico del fenómeno del ALBA debe establecer tres distinciones conceptuales muy claras:

1) Una distinción entre su ideario filosófico y su programa y las prácticas políticas concretas. Esa diferenciación es importante no solo desde un punto de vista analítico sino también ético, pues si el programa merece todos los respetos como propuesta hilvanada por valores humanistas, no puede afirmarse lo mismo de las prácticas en todas las ocasiones. En cualquier caso, el rigor académico exige necesariamente tomar distancias tanto de la demonización que hacen del proyecto los actores neoliberales como de la apología acrítica de muchos movimientos sociales de izquierda (como el citado ATTAC y muchos otros a ambos lados del Atlántico) quienes, en aras de defender el programa humanista y altermundialista común, hacen juegos malabares para justificar prácticas políticas como la deriva autoritaria de Chávez, la pesada huella ecológica de los hidrocarburos venezolanos o la soja boliviana, o la resistencia numantina de la dictadura castrista a abrir paso a la democracia (ATTAC, 2010).

2) Una distinción entre el ALBA como organización supranacional y sus políticas y los regímenes y políticas de cada uno de sus miembros integrantes. De nuevo una distinción de consecuencias científicas y éticas importantes, teniendo en cuenta el ya descrito clima de confrontación que suscitan algunos de sus miembros. Las políticas del ALBA constituyen una esfera de análisis hasta cierto punto autónoma de las políticas nacionales de sus estados miembros, de la misma manera que lo son las de la UE o las de la ONU. Nadie tacha a la ONU de políticas dictatoriales o marxistas solo porque en ella se sienten regímenes que si lo son, como Cuba, 
China o Siria. Algo parecido puede predicarse del ALBA. Aunque las políticas de algunos de sus estados miembros puedan hacerse acreedoras de comprensibles críticas por parte de quienes no comparten el discurso del Socialismo del Siglo XXI, difícilmente puede entenderse - $\mathrm{y}$ mucho menos defenderse- una posición ultracrítica frente a los proyectos del ALBA en sí mismos. Los proyectos del ALBA son un ejercicio de soberanía económica entre estados soberanos que parte de objetivos teóricos de desarrollo y justicia social y sus propuestas aparecen como razonables en el papel. Y, en el fondo, poco novedosas, pues la mayor parte de sus ideas centrales (moneda y banco común, eliminación interna de aranceles, fondos estructurales, cooperativismo, grandes conglomerados industriales participados por varios países, estructura organizativa incluso la propuesta de cooperación militar) tienen un precedente que conocemos muy bien: la Unión Europea (euro, BCE, empresas como Airbus, la Comunidad del Carbón y del Acero, etc.).

3) Una cuestión diferente es si el ALBA está siendo eficaz para lograr dichos objetivos de desarrollo y justicia social, o si lo será en el futuro. O si su eficacia está siendo, o previsiblemente lo será, superior a otro tipo de estrategias de integración regional como los TLCs con Estados Unidos y la Unión Europea por los que han optado otros estados latinoamericanos. Y aquí es donde un análisis serio debe hacer la última distinción: distinción entre los programas y sus difícilmente reprochables objetivos y los logros o fracasos económicos que las políticas concretas del ALBA, y de cada uno de sus países miembros, están alcanzando en la práctica. Es cierto que el ALBA es aún una institución muy joven y también que los datos estadísticos disponibles no permiten ofrecer conclusiones definitivas. Pero si nos acercamos al caso de Venezuela en particular, once años ininterrumpidos de gobierno son ya un lapso de tiempo razonable para poder emitir alguna valoración. En ese sentido se debe denunciar de nuevo la demagogia de los análisis apocalípticos de los críticos neoliberales 
pero tampoco se puede caer, por el otro extremo, en la defensa a ultranza del modelo como hacen sus ideologizados defensores. Los datos disponibles no permiten, por el momento, decantarse por un modelo económico o por el otro.

Investigaciones independientes (WEISBROT; RAY; SANDOVAL, 2009) e incluso los datos suministrados por la CIA (CIA, 2010) muestran que las economías del ALBA han experimentado un crecimiento notable en los últimos años. Sin embargo, no podemos afirmar con certeza que ese crecimiento sea resultado del cambio de paradigma propugnado por el ALBA o los gobiernos socialistas que lo integran. El resto de las economías latinoamericanas se ha comportado también en términos semejantes, con independencia de su programa económico (CIA, 2010). Las tasas de crecimiento más altas las presenta, de hecho, Perú, uno de los "traidores" vendidos al libre comercio y a una economía liberalizada, lo que hace añicos cualquier análisis maniqueo de la cuestión. Un bolivariano o un altermundialista convencido probablemente respondería a este argumento diciendo que los indicadores macroeconómicos no son necesariamente una medida de bienestar y no le faltaría, sin duda, un punto de razón. La política del ALBA y del "Socialismo del Siglo XXI” muestra quizá su mayor éxito en el campo del Desarrollo Humano. Estos logros son incluso es reconocidos por sus más feroces enemigos: Según el CIA Factbook, la tasa de analfabetismo en Venezuela en 1999, antes de que Chávez llegara al poder, era de 8,9\% (ELLIOT, 2008). En 2010 se había reducido a 6,6 (CIA, 2010). Pero, con muy pocas excepciones, la mayoría de los países del Tercer Mundo han mejorado su Índice de Desarrollo Humano en la última década (PNUD, 2010). Si comparamos de nuevo Venezuela con Perú a partir de las cifras ofrecidas por el PNUD, elaboradas con un conjunto de indicadores que corrigen la distorsión provocada por una simple medición del desarrollo en base al crecimiento macroeconómico (es decir, a partir de esos indicadores que el ALBA pretende privilegiar, como la educación o la salud) los resultados ofrecen aún más elementos para la reflexión: en 1997, la Venezuela pre-bolivariana se situaba en el puesto 48 del ránking mundial de IDH con un valor de 0,792 mientras Perú se encontraba en el 80, con 0,739. Tras 11 años de régimen chavista y 7 de ALBA, Venezuela ocupa ahora el puesto 75 y su puntuación absoluta ha descendido a 0,716. Por el contrario Perú ha adelantado 17 posiciones y está ahora por delante de Venezuela tanto en términos relativos (puesto 63) como absolutos $(0,788)$. ¿Complot del PNUD para sabotear 
la gestión del ALBA o del chavismo manipulando los datos? Sería muy difícil defender ese argumento. El ejercicio comparativo también genera muchas preguntas cuando pasamos al terreno de las políticas sociales: teniendo en cuenta su abolengo ideológico sería lógico esperar que los países del ALBA ocuparan mayoritariamente los primeros puestos latinoamericanos en gasto público en educación y salud (como porcentaje del PIB), con independencia de la efectividad real de este gasto. La realidad, tal y como nos la presentan los datos del PNUD, se escapa de nuevo a esquemas maniqueos: la Colombia del derechista Uribe es la que presenta las cifras más elevadas en ambos sectores. ¿Y qué decir de otros indicadores como los que reflejan el grado de respeto al medio ambiente? El religioso fervor ecológico de la agenda socialista queda muy atemperado cuando descendemos desde las grandes declaraciones de principios a los hechos de la economía real. Los gobiernos de países como Venezuela y Bolivia son perfectamente conscientes de que su principal activo económico son sus enormes reservas de hidrocarburos o la enorme potencialidad de intensificación de su agricultura. Bolivia había empezado a sustituir la selva virgen de Beni y Pando con campos de soja durante los gobiernos liberales que precedieron al MAS. Pero con Morales en el poder el frente agrícola ha seguido aumentando -la deforestación es tan brutal que puede constatarse con un simple vistazo en Google Earth- y el ALBA tiene una responsabilidad capital en ese proceso pues esa soja constituye la única exportación significativa de Bolivia a Venezuela. Venezuela, por su parte, viene contaminando seriamente el lago Maracaibo con vertidos de petróleo desde principios del siglo XX, sin que la década del régimen bolivariano haya supuesto un cambio significativo. Estas contradicciones serán muy difíciles de resolver. Venezuela puntúa casi seis veces por encima de Perú o Colombia en emisiones de CO2 per cápita (PNUD, 2010)

Datos como estos plantean también otro tipo de preguntas: ¿Por qué tanto ruido- por ambos bandos- para lo que parecen tan magros resultados? La respuesta, ya lo hemos dicho, se encuentra en las implicaciones geopolíticas del ALBA. Con respecto a sus resultados concretos las cifras de momento solo pueden conducirnos a la prudencia. Todo parece indicar que el ALBA no está teniendo implicaciones diferenciales en la práctica. No está, por el momento cambiando el mundo. Pero también debemos reconocer que su proyecto es de una ambición tan mayúscula que necesitará de varias décadas para hacer crecer sus semillas. Mantener el 
ALBA bajo estricta y ecuánime observación para seguir evaluando sus procesos será, sin duda, una fascinante aventura de investigación para los años venideros.

\section{The ALBA-TCP (Bolivarian Alliance for the Americas-People's Trade Agreement): Analysis of a Latin American Regional Integration Project with a deep alter-globalization dimension.}

\section{Abstract}

The ALBA-TCP is one of the international organizations most recently created. It is undoubtedly an original project, different from the pre-existing formulas of regional integration: it aims at steering the economic and trade relations between countries to avoid or minimize market competition and encourage cooperation and synergies. And all this as an expression of an postmodern ideological collage where almost all the currents of the leftist thought are present. The ALBA is in the midst of a geopolitical and ideological confrontation of a continental scale that greatly skews the objectivity of analysis. This article aims at overcoming these biases by presenting a rigorous academic analysis. The paper examines the historical circumstances surrounding the birth and evolution of ALBA and ventures into the analysis of its ideological program and its concrete projects, showing their convergence with the global justice movement in Latin America and worldwide. Finally, some development statistics are shown to assess the practical results of the economic policies of this regional bloc.

Keywords: ALBA-TCP, Alter-globalization, Trade Agreements, Regional Integration, International Organizations, XXIst Century Socialism.

\section{Referencias}

ALI, T. Pirates of the Caribbean: axis of hope. London: Verso. 2006.

ALIANZA BOLIVARIANA PARA LOS PUEBLOS DE NUESTRA AMERICA TRATADO DE COMERCIO DE LOS PUEBLOS. Declaración conjunta entre el presidente de la república bolivariana de Venezuela y el presidente del consejo de 
estado de la república de Cuba para la creación del ALBA. La Habana, 14 dic. 2004. Disponible em: <http://www.alianzabolivariana.org/>. Acesso em: 15 maio 2011.

ALIANZA BOLIVARIANA PARA LOS PUEBLOS DE NUESTRA AMERICA TRATADO DE COMERCIO DE LOS PUEBLOS. [Website]. 2010. Disponible em: $<$ http://www.alianzabolivariana.org/>. Acesso em: 20 maio 2011.

ALTMANN, J. ALBA: ¿un proyecto alternativo para América Latina? Madrid: Real Instituto Elcano, 2008.

ANTI DIFAMATION LEAGUE. The Chavez Regime: fostering anti-semitism and supporting radical islam. New York, 6 nov. 2006. Disponible em: <http://www. adl.org/main_International_Affairs/venezuela_anti_semitism_report.htm?Multi_ page_sections $=$ sHeading_8 $>$. Acesso em: 20 maio 2011.

ASSOCIATED PRESS. Chávez Seeks Arab Support for Oil-Backed Currency to Challenge U. S. Dollar. New York, 31 mar. 2009.

ATTAC-FRANCE. Manifeste altermondialiste: bâtir un monde solidaire, écologique et démocratique. 2006. http://www.manifeste.attac.org/ Acesso em: 15 maio 2011.

AZZI, D.; HARRIS, D. ALBA: Venezuela's answer to free trade, focus on the global south Occasional paper n. 3. Bangkok: Chulalongkorn Universty, 2006.

BADENES, D. Chávez propone formar una red de empresas recuperadas del Sur. El Correo, 27 oct. 2005. http://www.elcorreo.eu.org/?Chavez-propone-formar-unared-de\&lang=fr. Acesso em: 15 maio 2011.

BALDWIN, R. Failure of the WTO Ministerial Conference at Cancun: Reasons and Remedies. The World Economy.Wiley\&sons Inc., Hoboken, New Jersey,v. 29, n. 6, p. 677-696, jun. 2006.

BARTLEY, K.; O'BRIAIN, D. The revolution will not be televised. [DVD]. (Galway, Ireland: Power Pictures, Irish Film Board, 2003.

BBC NEWS. Obama says Honduras coup illegal. 29 jun. 2009. Disponible em: $<$ http://news.bbc.co.uk/2/hi/americas/8125292.stm>. Acesso em: 16 maio 2011

BBC NEWS. US expands Axis of Evil. 6 mayo 2002. Disponible em: <http://news. bbc.co.uk/2/hi/americas/1971852.stm>. Acesso em: 16 maio 2011. 
BREMER,C.Formerguerrillaswin powerinElSalvador. TheIndependent, Londres, 16 mar. 2009 http://www.independent.co.uk/news/world/americas/former-guerrillas -win-power-in-el-salvador-1645867.html. Acesso em: 16 maio 2011

CABRERA LEMUZ, A. La complementariedad económica: la mejor vía al desarrollo antes que la competitividad. Alianza Bolivariana para los Pueblos de Nuestra America - Tratado de Comercio de los Pueblos. 2010. Disponible em: $<$ http://www.alternativabolivariana.org/modules.php?name=News\&file=article\&s $\mathrm{id}=5547>$. Acesso em: 16 maio 2011

CARTER, J. President Jimmy Carter: Venezuela Election Trip Report, August 13-18, 2004. The Carter Center. Atlanta, 2004. Disponible em: < http://www. cartercenter.org/news/documents/doc1801. html>. Access in: 16 maio 2011

CASSEN, B. ¿Hacia el "post-altermundialismo"? In: REBELIÓN. Otro mundo es posible. 2010. Disponible em: <http://www.rebelion.org/noticia.php?id=98474>. Acesso em: 16 maio 2011

CASSEN, B.; VENTURA, C. ¿Qué altermundialismo después del fin del neoliberalismo?. In: REBELIÓN. Otro mundo es posible. 2008. Disponible em: $<$ http://www.rebelion.org/noticia.php?id=73083>. Acesso em: 16 maio 2011

CASTELLS, M. The Power of Identity. Cambridge: Blackwell, 1997. (The information age: economy, society and culture, v. 2).

CBS NEWS. In His Own Words: Obama's Communist Manifesto. 8 sep. 2009. Disponible em: <http://www.cbsnews.com/8301-504365_162-5295526-504365. html>. Access in: 25 abr. 2011.

CLARK, W. The Real Reasons for the Upcoming War with Iraq: a macroeconomic and geostrategic analysis of the unspoken truth. Boston: Independent media center, 2003. Disponible em: $<$ http://www.fable.it/iraq/oil.pdf $>$. Access in: 25 apr.2011

CRESPO, P. The Other "Axis of Evil". Foundation for Defense of Democracies. Washington, 30 Jun. 2003. Disponible em: <http://www.defenddemocracy.org/ index.php?option $=$ com_content $\&$ task $=$ view $\& i d=11772287 \&$ Itemid $=347>$. Access in: 25 apr. 2011.

DAILY TELEGRAPH. Former guerilla fighter Mujica wins Uruguay's presidential election. Londres, 30 nov. 2009. 
DE BRUIN, D. The Chavez ALBA initiative is the dawn of trouble for the Americas. Henry Jackson Society. Londres, 13 jun. 2008. Disponible em: <http:// www.henryjacksonsociety.org/>. Access in: 16 may 2011

DEMIRDJIAN, S. B. Redes transnacionales: aportes para la lectura sobre el caso americano de la alianza Social continental. Buenos Aires: Universidad de Buenos Aires, 2006. Disponible em: <http://halshs.archives-ouvertes.fr/docs/00/10/36/74/ PDF/Demirdjian.pdf >. Acesso em: 16 maio 2011

EL OJO DIGITAL. A Risky bet: Hugo Chávez overloads his Latin American Axis of Evil" to start Alvaro Uribe". 24 ago. 2010. Disponible em: <http://www.elojodigital. $\mathrm{com} /$ contenido/9333-risky-bet-hugo-chavez-overloads-his-latin-american-axisevil-start-alvaro-uribe>. Acesso em: 16 maio 2011.

EL PAÍS. Chávez cierra 34 emisoras de radio venezolanas críticas con su política. Madrid, 2 ago. 2009. Disponible em: <http://www.elpais.com/articulo/ internacional/Chavez/cierra/34/emisoras/radio/venezolanas/criticas/politica/ elpepuint/20090802elpepiint_3/Tes>. Acesso em: 18 maio 2011.

EL PAÍS. Chávez cierra el canal privado RCTV en medio de violentas protestas. Madrid, 28 mayo 2007. Disponible em: <http://www.elpais.com/articulo/ internacional/Chavez/cierra/canal/privado/RCTV/medio/violentas/protestas/ elpepuint/20070528elpepuint_6/Tes>. Acesso em: 18 maio 2011.

EL PAÍS. Chávez, aliado de las FARC. Madrid, 17 ene. 2008. Disponible em: $<$ http://www.elpais.com/articulo/internacional/Chavez/aliado/FARC/elpepuint/ 20080117elpepuint_7/Tes $>$. Acesso em: 18 maio 2011.

EL TROUDI, H. El Salto Adelante: la nueva etapa de la Revolución Bolivariana. Caracas: Ediciones de la Presidencia de la República, 2005.

EL UNIVERSAL. Honduras se retira del Alba. Caracas, 13 de enero, 2010. Disponible em: <http://www.eluniversal.com/2010/01/13/eco_ava_honduras-seretira-d_13A3281613.shtml>. Acesso em: 13 apr. 2011.

ELLIOTT, D. L. Power to the People or Power to the Populist?: locating the Bolivarian Revolution Amongst its Supporters \& Critics. Dalhousie: Dalhousie University, Tesis de grado, 2008.

FERMÍN, T.; EUDIS, F. Alternativa bolivariana para los pueblos de nuestra América: ¿la ruptura paradigmática de los modelos de integración? Espacio Abierto, Maracaibo, VE, v. 18, n. 2, p. 339-365, abr./jun. 2009. 
FORERO, J. Documents Show C.I.A. Knew of a Coup Plot in Venezuela. The New York Times. 3 dic. 2004. Disponible em: http://www.nytimes.com/2004/12/03/ international/americas/03venezuela.html. Access in: 8 maio 2011

FRITZ, T. ALBA contra ALCA: la alternativa bolivariana para las Américas: una nueva vía para la integración regional en Latinoamérica. Berlin: FDCL, 2007.

GARCIA MERIDA, W. The Balkanization of Bolivia. Global Research. Montreal, 23 sep. 2008. Disponible em: <http://www.globalresearch.ca/index. php? context=va\&aid=10312>. Acesso em: 10 maio 2011 .

GONZÁlEZ, J. Bienvenido al Eje del Mal. Alianza Bolivariana para los Pueblos de Nuestra America - Tratado de Comercio de los Pueblos. 2009. Disponible em: $<$ http://www.alternativabolivariana.org/modules.php?name=News\&file=article\&s id=2935 $>$. Acesso em: 16 maio 2011.

GOTT, R. Hugo Chávez and the Bolivarian Revolution. London: Verso, 2005.

HAWKINS, K.; HANSEN, D. Dependent Civil Society: círculos Bolivarianos in Venezuela. Latin American Research Review, Pittsburgh, v. 41, n. 1, p. 102-132, jan. 2006.

JOFRÉ LEAL, P. Álvaro García Linera: de la guerrilla a las urnas. Adital. 28 nov. 2005. Disponible em: <http://www.adital.com.br/site/noticia2. asp?lang=ES\&cod=20104>. Acesso em: 16 maio 2011.

KATZ, C. El torbelino de la integración. Comité para la anulación de la deuda del tercer mundo. 25 jul. 2006. Disponible em: <www.cadtm.org>. Acesso em: 30 mar. 2011.

LA NACIÓN. La deriva autoritaria de Chávez. 25 feb. 2010. Disponible em: $<$ http://www.lanacion.com.ar/1236871-la-deriva-autoritaria-de-chavez>. Acesso em: 16 may 2011.

LACLAU, E. Politics and Ideology in Marxist Theory: Capitalism, Fascism, Populism. London: NLB, 1977.

LANDER, E. Modelos alternativos de integração? projetos neoliberais e resistências populares: Observatório Social da América Latina. Boletin CLACSO, Buenos Aires, v. 5, n. 15, p. 45-56, sep./dic. 2004.

LIBERTAD DIGITAL INTERNACIONAL. Chávez cierra un MacDonald's y un Wendy's para poner una estatua de Fidel Castro. 17 abr. 2010. Disponible em: 
$<$ http://www.libertaddigital.com/mundo/chavez-cierra-un-mcdonalds-y-unwendys-para-poner-una-estatua-de-fidel-castro-1276390390/>. Acesso em: 16 mar. 2011.

LINARES, R. Venezuela, nuevos desafíos regionales: ALCA o ALBA. In: V. ALBA vs. ALCA. Caracas: CELARG, 2007.

LOS ANGELES TIMES. WikiLeaks on Latin America: Honduras coup 'illegal'. Los Angeles, 29 nov. 2010. Disponible em: http://latimesblogs.latimes.com/ laplaza/2010/11/wikileaks-latin-america-venezuela-honduras-paraguayargentina.html. Acesso em: 20 de maio 2011.

LUCAS, K. Rafael Correa: un extraño en Carondelet. Barcelona: Planeta, 2007.

LULA watch - focusing on Latin America's new "Axis of Evil". Free Republic, Fresno, California, v.1, n.10, 6 jun. 2003.

MANDER, B. Take a hike on the Wild Side of an Oil State. Financial times. 15 sep. 2008. Disponible em: $<$ http://search.ft.com/search?queryText=ALBA+chavez\&fts earchTypeSearch=type_news $>$. Acesso em: 16 may 2011.

MAXWELL, K. The long shadow of Hugo Chávez: a sympathetic book defends Venezuela's strongman. Foreign Affairs, New York, Volume 79, Number 5 p. 53-55, sep./oct. 2000.

MAYOBRE, E. La propuesta Petroamérica y la Integración Energética de América Latina y El Caribe. Caracas: Instituto Latinoamericano de Investigaciones Sociales (ILDIS), 2005.

MORA Y LEÓN, A. M. The communist menace reappears in South America. American Thinker, 19 sep. 2005.http://www.americanthinker.com Acesso em: 10 may 2011.

MORALES MANZUR, J. C.; MORALES GARCÍA, L. Origen y naturaleza de la Alternativa Bolivariana para las Américas. Polis, UAM, Mexico, v. 3, n. 1, p. 60, jan. 2007.

NAIM, N. Alternativa Bolivariana para las Américas: una Propuesta histórico política al ALCA. Geoenseñanza. Universidad de los Andes, San Cristóbal, Venezuela, v. 9, n. 1, p. 57-73, jan-jun. 2004. 
NICARAGUA. Presidencia de la Républica. Presentación del Plan de Desarrollo Humano del Gobierno de Unidad y Reconciliación Nacional. Manágua, 2008. Disponible em: <http://www.presidencia.gob.ni/index.php?option=com_content\& view=article\&id=101:un-plan-un-espiritu-un-compromiso-salir-de-la-pobreza\&catid=46:junio2008\&Itemid=54\&showall=1>. Acesso em: 16 maio 2011.

OPPENHEIMER, A. ¿'Venecuba’ o ‘Cubazuela’? El País. 18 mayo 2010. Disponible em: <http://www.elpais.com/articulo/internacional/Venecuba/Cubazuela/elpepiint/ 20100518elpepiint_9/Tes>. Acesso em: 16 maio 2011.

ORGAZ, N. Rosario Murillo, La Nueva Ideóloga del FSLN: Evolución de la Revolución. El Socialista Centroamericano. 2008. Disponible em: <http://www. izquierda.info/modules.php? name $=$ News\&file $=$ article\&sid=3087> . Acesso em: 18 maio 2011.

PALACIOS, Angel. Puente Llaguno: claves de una masacre. Vídeo documental. Asociación Nacional de Medios comunitarios, libres y alternativos, 2004. 103 min. Disponible em: <http://www.pordescargadirecta.com/documentales-latino/4447puente-llaguno-claves-una-masacre-vhsrip-latino-megaupload-rapidshare/>. Acesso em: 03 abr. 2011.

PAUL, R. The end of dollar hegemony, Speech in the U.S. House of Representatives. 15 Feb. 2006. Disponible em: <http://satrong.org/content/miscellaneous/ DollarHegemony.pdf $>$. Acesso em: 18 may 2011.

PEÑA ESCLUSA, A. Chavez, Ahmadinejad and the Next "Missile Crisis". Accuracy in Media. Washington, D.C., 19 mar. 2009. Disponible em: <http://www.aim.org/guestcolumn/chavez-ahmadinejad-and-the-next-missile-crisis/> . Acesso em:18 may 2011.

PETIT, M. Cubanos al mando en Venezuela. La Prensa, Local, 20 mar. 2011. Disponible em: <http://www.laprensa.com.ni/2011/03/20/reportajesespeciales/55371>. Acesso em: 03 abr. 2011.

POLET, F. Clés de lecture de l'altermondialisme. Charleroi: CETRI ; Couleur livres, 2008.

PREBISCH, R. Towards a Dynamic Development Policy for Latin America. New York: United Nations, 1963.

PRIMAVERA, H. Redes de trueque en América latina: ¿quo vadis?” El Catoblepas. Revista Crítica del Presente, Madrid, n. 7, sep. 2002, Disponible em: http://nodulo. org/ec/2002/n007p04.htm. Acesso em: 03 abr. 2011. 
PROGRAMA DE DESARROLLO DE NACIONES UNIDAS. Informes de Desarrollo Humano: 1990-2010. New York, 2010. Disponible em: <http://hdr.undp. org/>. Acesso em: 03 abr. 2011.

RADIO TELEVISIÓN ESPAÑOLA. Venezuela cierra los Macdonald's por dos dias. Madrid,11 oct.2008.Disponibleem:<http://www.rtve.es/alacarta/videos/television/ venezuela-cierra-los-mcdonalds-por-dos-dias $/ 312736 / ? \operatorname{modl}=\mathrm{COMTS}>$. Acesso em: <http://hdr.undp.org/>. Acesso em: 03 abr. 2011.

RAMÍREZ, C. V. (2006). "Venezuela in the Eye of the Hurricane: Landing an Analysis of the Bolivarian Revolution", Journal of Latin American Anthropology, Florida International University, Miami, v. 11, n. 1, p. 173-186, jan.-jun. 2006.

REICH, O. J. Chavez's Covert War. Foreign Policy., 28 ago. 2009. Disponible em: <http://www.foreignpolicy.com/articles/2009/08/28/chavez_s_covert_war>. Acesso em: 03 abr. 2011.

REICH, O. J. Latin America's Terrible Two. Fidel Castro and Hugo Chávez Constitute an Axis of Evil. National Review: Digital. 11 abr. 2005. Disponible em: <http://nrd. nationalreview.com/article/?q=NTUxYWYyMmI0ZmNhMWZmYWVmYjljNW E4ZDQyYmE4NGE=>. Accesso em: 03/04/2011.

RICO, M. Los papeles de las FARC acusan a Chávez. El País, 10 mayo 2008. Disponible em: <http://www.elpais.com/articulo/internacional/papeles/FARC/ acusan/Chavez/elpepuint/20080510elpepiint_6/Tes>. Acesso em: 13 abr. 2011.

ROJO, A. Globalización, integración mundial y federalismo. Revista de Estudios Políticos, Madrid, n. 109, p. 29-72, jul/sept. 2000

ROMERO, C. Venezuela y Estados Unidos: ¿una relación esquizofrénica? Nueva Sociedad, Caracas, n. 206, p. 78-93, nov./dic. 2006.

SAGUIER, Marcelo. The Hemispheric Social Alliance and the Free Trade Area of the Americas Process: The Challenges and Opportunities of Transnational Coalitions against Neo-liberalism. Globalizations, Routledge, Londres, v. 4, n. 2, p. 251-265, abril 2007. Disponible em: <http://dx.doi.org/10.1080/14747730701345267>. Acesso em:13 apr. 2011.

SANAHUJA, J. A. Del regionalismo abierto al regionalismo post-liberal. Crisis y cambio en la integración regional en América Latina. Anuario de la Integración Regional de América Latina y el Gran Caribe, Managua, n. 7, p. 11-54, 2009 
SCHIFTER, M. Slouching towards Authoritarianism. Foreign Affairs, New York, 7 nov. 2007. Disponible em: <http://www.foreignaffairs.com/articles/64251/michaelshifter/slouching-toward-authoritarianism>. Acesso em: 13 apr. 2011

SCHOEN, D. E.; ROWAN, M. Threat closer to home: Hugo Chavez and the war against America: A chilling account of Hugo Chávez's shadow war on the United States, New York: Free Press, 2009.

SEOANE, J.; TADDEI, E. El nuevo internacionalismo y los desafíos de los movimientos populares latinoamericanos frente a la crisis capitalista. Viento Sur, San Sebastian, Espanha, n. 107, p. 63-74, dic. 2009.

SERRANO, P. Hemos venido a Mar del Plata a enterrar el ALCA. Rebelión, Madrid, 5 nov. 2005, Disponible em: <http://www.rebelion.org/noticia.php?id=22336>. Acesso em: 13 abr. 2011

SISTEMA ECONÓMICO LATINOAMERICANO Y DEL CARIBE. Informe sobre el Proceso de Integración Regional: 2008-2009. Local, 2009. Disponible em: <www.sela.org/.../2009/.../T023600003818-0-Informe_sobre_el_proceso_de_ integracion_regional,_2008-2009.pdf>. Acesso em: 13 abr. 2011

STEFANONI, P.; DO ALTO, H. La revolución de Evo Morales: de la coca al palacio. Buenos Aires: Capital Intelectual, 2007.

TEXIER, B. The Latin-American “Axis of evil”. AGIR, Revue General de Stragtegie, Paris, n. 15, Oct. 2003. Disponible em: <http://www.societe-de-strategie.asso.fr/ en/agir.php?id=15\#sommaire $>$. Acesso em: 13 apr. 2011

THE ECONOMIST. Hugo Chávez's government: The wrecking of Venezuela, 13 mayo 2010, Disponible em: <http://www.economist.com/opinion/displaystory. cfm?story_id=16109302>. Acesso em: 13 apr. 2011

THE NEW YORK TIMES. Cuba, Bolivia, Venezuela Reject U.S. Trade. 30 abr. 2006. Disponibleem:<http://www.nytimes.com/2006/04/30/world/americas/30iht-web.0430 trade.html?scp=10\&sq=ALBA\%20chavez\&st=cse $>$. Acesso em: 16 may 2011.

TOURAINE, A. La voix et le regard: Sociologie des mouvements sociaux. Paris: Seuil, 1978.

TUSSIE, D. Latin America: contrasting motivations for regional projects. Review of International Studies, Cambridge, n. 35, p. 169-188, mar. 2009. Copyright_British International Studies Association. doi:10.1017/S026021050900847X 
VARGAS LLOSA, A. Honduras' Coup is President Zelaya's Fault. The Washington Post, Washington, 1 jul. 2009, Disponible em: <http://www.washingtonpost.com/ wp-dyn/content/article/2009/07/01/AR2009070103210.html>. Acesso em: 13 apr. 2011.

VENEZUELA. Constitución de la República Bolivariana de Venezuela Gaceta Oficial $n^{\circ}$ 36.860. Caracas, 30 dic. 1999.

VENEZUELA. Gobierno Bolivariano. Ministerio del Poder Popular para la Comunicación y la Información. Guyana manifiesta voluntad de unirse al ALBA. Prensa Presidencial. Caracas, 21 jul. 2010. Disponible em: <http://www.minci.gob. ve/a_r_r/28/201215/guyana_manifiesta_voluntad.html>. Acesso em: 13 apr. 2011.

VINOGRADOFF, L. Chávez ordena a la justicia el cierre de Globovisión. Diario $A B C, 29$ mayo 2009. Disponible em: <http://www.abc.es/20090529/internacionaliberoamerica/chavez-ordena-cierre-globovision-200905291600.html>. Acesso em: 23 abr. 2011.

VULLIAMY, E. Venezuela Coup Linked to Bush Team. The Observer International. Londres, 21 abr. 2002. Disponible em: <http://observer.guardian.co.uk/ international/story/0,6903,688071,00.html>. Acesso em: 23 apr. 2011

WEISBROT, M.; RAY, R.; SANDOVAL, L. El gobierno de Chávez después de 10 años: Evolución de la economía e indicadores sociales. Washington, D.C: Center for Economic and Policy Research, 2009.

WEISBROT, M.; SANDOVAL, L.; ROSNIK, D. Poverty Rates in Venezuela; getting the numbers right. International Journal of Health Services, Amityville, NY, v. 36, n. 4 , p. 813-823, oct. 2006.

WEISBROT, M.; SCHMITT, J.; SANDOVAL, L. The Economic Impact of a U.S. Slowdown on the Americas. Washington D.C.: Center for economic and policy research, 2008. 


\section{Para publicar na revista Universitas}

Relações Internacionais, entre no endereço eletrônico www.publicacoesacademicas.uniceub.br. Observe as normas de publicação, facilitando e agilizando o trabalho de edição. 